\title{
Revising the European Society of Gastrointestinal Endoscopy (ESGE) research priorities: a research progress update
}

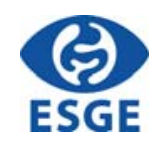

Authors

Pradeep Bhandari ${ }^{1}$, Gaius Longcroft-Wheaton ${ }^{1} \odot$, Diogo Libanio ${ }^{2,3} \odot$, Pedro Pimentel-Nunes $^{2,3}$, Eduardo Albeniz ${ }^{4} \odot$, Mathieu Pioche ${ }^{5}$, Reena Sidhu ${ }^{6}$, Cristiano Spada ${ }^{7,8}$, Andrea Anderloni ${ }^{9}$, Alessandro Repici ${ }^{10,11}$, Rehan Haidry ${ }^{12}$, Marc Barthet $^{13}$, Helmut Neumann ${ }^{14,15} \odot$, Giulio Antonelli ${ }^{9,16,17}$, Alberto Testoni ${ }^{18}$, Thierry Ponchon ${ }^{5}$, Peter D. Siersema ${ }^{19}$, Lorenzo Fuccio $^{20} \odot$, Cesare Hassan ${ }^{16}$, Mario Dinis-Ribeiro 2,3

Institutions

1 Department of Gastroenterology, Portsmouth University Hospital NHS Trust, Portsmouth, UK

2 Gastroenterology Department, Portuguese Oncology Institute of Porto, Porto, Portugal

3 Center for Research in Health Technologies and Information Systems (CINTESIS), Faculty of Medicine, Porto, Portugal

4 Gastroenterology Department, Endoscopy Unit, Complejo Hospitalario de Navarra, NavarrabiomedUPNA-IdiSNA, Pamplona, Spain

5 Gastroenterology Division, Edouard Herriot Hospital, Lyon, France

6 Academic Department of Gastroenterology, Royal Hallamshire Hospital, Sheffield, UK

7 Digestive Endoscopy and Gastroenterology, Fondazione Poliambulanza, Brescia, Italy

8 Università Cattolica del Sacro Cuore, Rome, Italy

9 Gastroenterology and Digestive Endoscopy Unit, Ospedale dei Castelli, Ariccia, Rome, Italy

10 Department of Biomedical Sciences, Humanitas University, Milan, Italy

11 Digestive Endoscopy Unit, IRCSS Humanitas Research Hospital, Milan, Italy

12 Department of Gastroenterology, University College London Hospitals, London, UK

13 Department of Gastroenterology, Hôpital Nord, Assistance publique des hôpitaux de Marseille, Marseille, France

14 Department of Medicine I, University Medical Center Mainz, Mainz, Germany

15 GastroZentrum Lippe, Bad Salzuflen, Germany

16 Nuovo Regina Margherita Hospital, Rome, Italy

17 Department of Translational and Precision Medicine, "Sapienza" University of Rome, Rome, Italy

18 Vita Salute, San Raffaele Hospital, Milan, Italy

19 Department of Gastroenterology and Hepatology, Radboud University Medical Center, Nijmegen, The Netherlands
20 Department of Medical and Surgical Sciences, IRCCS Azienda Ospedaliero-Universitaria di Bologna, Bologna, Italy

published online 1.4 .2021

Bibliography

Endoscopy 2021; 53: 535-554

DOI 10.1055/a-1397-3005

ISSN 0013-726X

(c) 2021. European Society of Gastrointestinal Endoscopy

All rights reserved.

This article ist published by Thieme.

Georg Thieme Verlag KG, Rüdigerstraße 14,

70469 Stuttgart, Germany

丹 Appendix 1s

Supplementary material is available under

https://doi.org/10.1055/a-1397-3005

Corresponding author

Pradeep Bhandari, MD, Portsmouth University Hospitals NHS

Trust, Southwick Hill Road, Cosham, Portsmouth, PO6 3LY,

United Kingdom

Pradeep.Bhandari@porthosp.nhs.uk

\section{ABSTRACT}

Background One of the aims of the European Society of Gastrointestinal Endoscopy (ESGE) is to encourage high quality endoscopic research at a European level. In 2016, the ESGE research committee published a set of research priorities. As endoscopic research is flourishing, we aimed to review the literature and determine whether endoscopic research over the last 4 years had managed to address any of our previously published priorities.

Methods As the previously published priorities were grouped under seven different domains, a working party with at least two European experts was created for each do- 
main to review all the priorities under that domain. A structured review form was developed to standardize the review process. The group conducted an extensive literature search relevant to each of the priorities and then graded the priorities into three categories: (1) no longer a priority (well-designed trial, incorporated in national/international guidelines or adopted in routine clinical practice); (2) remains a priority (i.e. the above criterion was not met); (3) redefine the existing priority (i.e. the priority was too vague with the research question not clearly defined).

Results The previous ESGE research priorities document published in 2016 had 26 research priorities under seven domains. Our review of these priorities has resulted in sev- en priorities being removed from the list, one priority being partially removed, another seven being redefined to make them more precise, with eleven priorities remaining unchanged. This is a reflection of a rapid surge in endoscopic research, resulting in $27 \%$ of research questions having already been answered and another $27 \%$ requiring redefinition.

Conclusions Our extensive review process has led to the removal of seven research priorities from the previous (2016) list, leaving 19 research priorities that have been redefined to make them more precise and relevant for researchers and funding bodies to target.

\section{SOURCE AND SCOPE}

This progress report is an official statement from the European Society of Gastrointestinal Endoscopy (ESGE). It updates the 2016 ESGE document on the key unanswered research questions within gastrointestinal endoscopy.

\section{Introduction}

The practice of digestive endoscopy is evolving at a very rapid pace. This is driven by the development of new devices led by industry and the development of new techniques led by endoscopists. Whilst innovations are welcome, a robust system of testing and trialing these innovations would help to ensure that the benefits to patients outweigh any potential harms from such innovation. This requires a robust culture of good quality research.

There are distinct differences between traditional drug development and research compared with endoscopy device development and research. A drug cannot be licensed without large regulatory multicenter phase III randomized controlled trials (RCTs), whereas an endoscopy device can be licensed after a device safety study without robust efficacy data. One of the aims of the European Society of Gastrointestinal Endoscopy (ESGE) is to encourage, facilitate, and support high quality endoscopic research at a European level.

In 2014, the ESGE research committee set out to produce a list of key research priorities in the field of digestive endoscopy. These were developed over a 2-year period in a three-step process. This started with various ESGE committees generating a list of research questions, followed by the research committee refining and consolidating these questions under specific endoscopic domains, and finally prioritization voting by ESGE members to establish 26 research priorities under seven endoscopic domains. ESGE finally published a list of top research priorities in 2016 [1]. A published list is particularly useful for young researchers, industry looking for innovations, and funding bodies

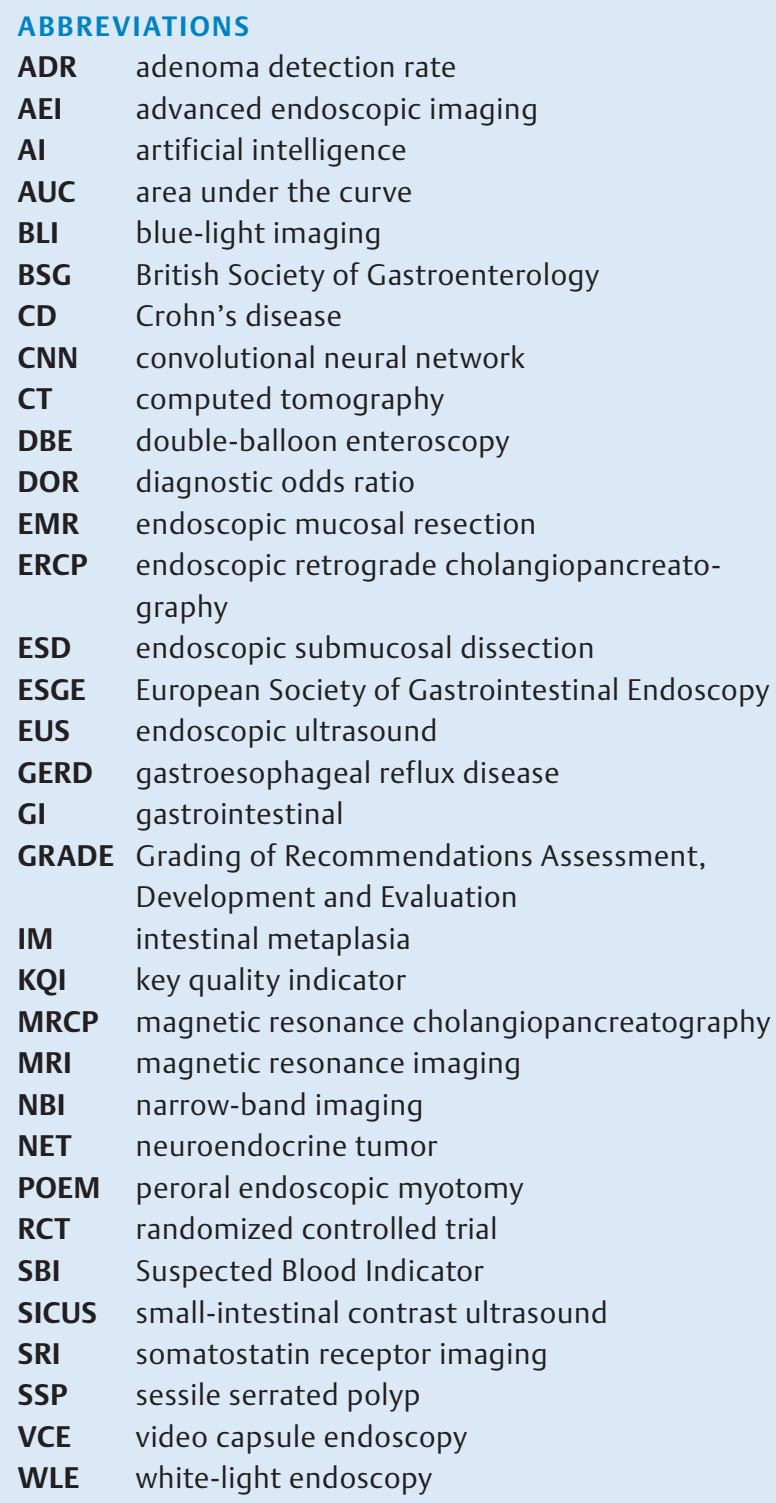


trying to decide on funding priorities. It is also important to note that endoscopic research is also being performed at a rapid pace and a topic that is considered to be a top priority today might not remain a priority in a years' time.

A PubMed search revealed that in the last 5 years, 96379 articles were published on endoscopy. This gives an idea of the speed at which research in the field of endoscopy is progressing. It may also bring into question the relevance of the ESGE published research priorities as of today. Therefore, we decided to conduct a thorough review of the literature to assess the current relevance of the ESGE set of research priorities. The aim of this review was to scrutinize the published literature related to each of the 26 priorities and decide whether or not the topic should continue to be a priority. If the topic remained a priority, we aimed to redefine the priority where necessary.

\section{Methods}

A preliminary meeting of the research committee was held at the ESGE Days meeting held in Prague in April 2019 to share methods, aims, timelines, and the entire position paper process. As the previously published priorities were grouped under seven different domains, a working party for each domain was created, with each group having at least two European experts, to review all the priorities under that domain. A structured review form was developed to standardize the review process (Appendix $1 \mathrm{~s}$, see online-only Supplementary material).

The working parties independently carried out a systematic search for, and analysis of, the literature relevant to their domains, using the major electronic databases (PubMed, Scopus, Cochrane, and Embase), limiting the search period to 1 January 2015 to 31 May 2020. Relevant evidence was graded according to the Grading of Recommendations Assessment, Development and Evaluation (GRADE) system [2]. Once these data had been collected, a web-based meeting of the entire group was held in July 2020 to review all the evidence and make a decision as to relevance of each previously published priority. The consensus group included 18 participants and was led by a chairman (P. B.).

Overall, 27 research priorities were submitted to the global consensus group for an open discussion driven by the chairman. This higher number of research priorities was the result of one research priority from the upper gastrointestinal (GI) domain in the 2016 paper ("What is the role of advanced imaging in dysplasia detection in Barrett's esophagus and squamous esophagus in high risk patients or intestinal metaplasia in the stomach") being split into two, because different priorities were provided for dysplasia in the esophagus vs. intestinal metaplasia (IM) in the stomach. Each revised research priority was discussed and a final decision was taken unanimously, placing it into one of three different categories: (1) no longer a priority (well-designed trial, incorporated in national/international guidelines or adopted in routine clinical practice); (2) remains a priority (i.e. the above criterion was not met); (3) redefine the existing priority (i.e. the priority was too vague with the research question not clearly defined).

\section{Generic priorities}

\section{How do we define the correct surveillance interval following initial endoscopic diagnosis?}

\section{RECOMMENDATION}

Redefine.

What is the impact of endoscopic surveillance on incidence and disease-specific survival?

Since the publication of the previous Research Priorities document [1], many guidelines specifically addressing the topic of surveillance following the endoscopic diagnosis of precancerous or cancerous conditions have been published by the ESGE, including surveillance of Barrett's esophagus [3], for gastric atrophy and IM [4], post-polypectomy [5], and after (endoscopic and surgical) resection of colorectal cancer [6]. Multiple observational studies have been published addressing the stratification of patients undergoing surveillance for precancerous or cancerous conditions [7-10]. These studies propose clinically useful stratification of such populations into high and low risk groups. Therefore, the question "who is at risk and what should the surveillance interval be?" has been successfully addressed. However, these studies have not yet assessed whether the surveillance intervention is able to reduce incidence or mortality and this deserves to be addressed in long-term randomized trials with clinically relevant end points (i.e. European Polyp Surveillance [EPoS], NCT02319928 [11]).

The surveillance interval-related question is no longer a priority but should be redefined to address the impact of endoscopic surveillance on incidence and disease-specific survival.

\section{How do we correctly utilize advanced endoscopic imaging?}

\section{RECOMMENDATION}

Redefine.

How can advanced endoscopic imaging be implemented to change clinical practice?

In lower GI endoscopy, several studies have evaluated the accuracy of advanced endoscopic imaging (AEI) for polyp detection and characterization $[12,13]$, so this aspect no longer represents a priority question. Similarly, how to implement a training program for $\mathrm{AEI}$ and how to maintain expertise has recently been addressed using objective methodology by a dedicated ESGE curriculum for optical diagnosis [14]. On the other hand, the clinical impact of this curriculum and ways to analyze its implementation are topics for future research. Similarly, the role of AEI in the upper GI tract has also been extensively explored [15]. There are ESGE standards that have already been set around the use of AEI [16].

However, AEl-assisted optical biopsy has still not replaced histological biopsy in clinical practice. Similarly, AEI has the potential to influence clinical decisions such as resect and discard 
for diminutive adenomas, diagnose and leave for diminutive hyperplastic polyps in the rectosigmoid region, and direct referral to surgery for deep invasive GI cancers or endoscopic resection for superficial cancers. However, this kind of implementation of $\mathrm{AEI}$ in our routine endoscopic practice has still not happened, although the advent of artificial intelligence (AI) has raised high hopes of making this a reality.

For this reason, the question should be redefined to look at how AEI can be implemented to change clinical practice.

\section{What are the best markers of endoscopy quality?}

\section{RECOMMENDATION}

Redefine.

How can we implement and monitor adherence to the key quality indicators (KQIs) and quantify the long-term benefits of such implementation, as well as developing and validating the patient experience-related KQIs?

ESGE has produced position statements [12,13,17-19] on the most appropriate performance and key quality indicators (KQIs) for a whole range of endoscopic procedures and techniques. In addition, specific domains and subdomains have been generated for each technique. The best markers of quality in endoscopy are well defined and there is substantial evidence supporting the use of the main KQIs in relation to the efficacy and safety of the procedures. Defining the KQIs is no longer a priority, but a number of proposed quality indicators related to patient experience are in their infancy, without any supporting evidence, so further work in this area is required.

Further research needs to be performed to develop strategies related to the implementation and monitoring of KQls. The priority related to quality in endoscopy should therefore be redefined to consider how we can implement and monitor adherence to the KQIs and quantify the long-term benefits of such implementation, while developing and validating the patient experience-related KQIs.

\section{What are the best ways to train endoscopists?}

\section{RECOMMENDATION}

No longer a priority.

Training for endoscopists has been the subject of research since the last research priorities document was published. The ESGE has been developing a series of curricula for training in various advanced endoscopic procedures [20]. Curricula for training in endoscopic submucosal dissection (ESD) [21], optical diagnosis [14], and small-bowel assessment [22] in Europe have already been published by the ESGE. The critical role of such publications has been in defining the key competencies for each technique and then developing training modules to achieve these competencies. As for training modalities, the most researched modalities are simulation-based training and training in AEl. Simulation-based training is the most researched topic and this has been summarized in a published Cochrane review and meta-analysis [23]. Therefore, the question "how to train" has to a large extent been addressed. The remaining question is related to post-training suboptimal performance and ways of tackling it.

\section{Upper gastrointestinal endoscopy}

\section{What is the correct surveillance strategy for atrophic gastritis and metaplastic gastritis?}

\section{RECOMMENDATION \\ Remains a priority.}

Since 2015, no study has compared different surveillance strategies for gastric premalignant conditions. In fact, even before 2015, only one RCT had evaluated different surveillance strategies for patients with these conditions, but even this study only considered patients with autoimmune gastritis [24]. In the last 5 years, several studies have confirmed the importance of surveillance in patients with these conditions and this is reflected in two recent guidelines that recommend new surveillance intervals, according to different risk factors [4,25]. However, both guidelines recognize that the timing for surveillance, even though similar in both, is based on expert opinion and is not evidence-based.

In this context, there is a need for well-designed randomized studies comparing different surveillance intervals for these patients. Moreover, these studies should also evaluate the influence of factors, such as the stage of gastritis (endoscopically and histologically), the presence of (in)complete IM, and a family history of gastric cancer, on the surveillance strategy. The impact of surveillance in these studies should be quantified, not only in terms of the prevention of gastric cancer, but also in terms of the detection of dysplasia or adenocarcinoma, the detection of neuroendocrine tumors (NETs), and also the progression to high risk stages for patients with low risk at baseline.

\section{What is the correct surveillance strategy for Barrett's esophagus?}

\section{RECOMMENDATION}

Remains a priority.

Several guidelines have recommended endoscopic surveillance at regular intervals for Barrett's esophagus. The supporting evidence is weak and such strategies vary between different settings, often being guided more by expert opinions than robust evidence $[3,26,27]$. Since the publication of the previous ESGE priorities, two systematic reviews have shown a survival advantage and lower risk of progression in patients undergoing endoscopic surveillance [28, 29]. No randomized trials on surveillance intervals have been published, but ESGE has pub- 
lished new guidelines suggesting the surveillance interval should be based on the length of Barrett's esophagus [3].

One randomized trial showed the advantage of wide-area transepithelial sampling (WATS) on random biopsies for the detection of high grade dysplasia and esophageal adenocarcinoma [30]. One feasibility randomized tandem endoscopy trial of the Seattle protocol vs. acetic acid chromoendoscopy showed that acetic acid-guided biopsies can dramatically reduce the number of biopsies taken per neoplasia detected, but a fully powered non-inferiority study would require 2828 patients [31]. Several prospective studies have shown the importance of a dedicated list and advanced imaging technologies, including narrow-band imaging (NBI) and confocal laser endomicroscopy. An evidence-based model for Barrett's surveillance following radiofrequency ablation suggests the possibility of reducing the number of surveillance endoscopies and increasing the surveillance interval based on the grade of dysplasia [32].

In conclusion, although guidelines are suggesting the prolongation of the surveillance interval in certain subgroups, this is not based on any good quality data, or on the availability of techniques/modalities to perform this. Barrett's surveillance is a rapidly evolving field, but defining and standardizing our strategies to show a meaningful impact on the outcome of Barrett's patients should remain a priority.

\section{When can anticoagulant medication be restarted following gastrointestinal bleeding?}

RECOMMENDATION

Remains a priority.

The right timing for anticoagulant and antiplatelet resumption following Gl bleeding remains uncertain. Recently a new class of drugs, direct oral anticoagulants (DOACs), has been introduced. There is a lack of good evidence on their management following $\mathrm{Gl}$ bleeding. High quality prospective studies should be prioritized to get direct data from patients. Two systematic reviews showed survival advantage after anticoagulant resumption, no RCT or prospective study has been published, but six retrospective studies were found [33-38]. Anticoagulant resumption increased the rate of $\mathrm{Gl}$ bleeding and decreased the rate of thromboembolism, with a net benefit on mortality [38].

In conclusion, results on the timing of resuming anticoagulation are often inconclusive. There is a need for randomized studies evaluating the net patient benefit of different timings for the re-introduction of anticoagulants with risk stratification to individualize treatment.

\section{What is the role of advanced imaging in the detection of dysplasia in Barrett's esophagus and squamous esophagus in high risk patients and for the detection of intestinal metaplasia in the stomach?}

RECOMMENDATION FOR BARRETT'S ESOPHAGUS

AND SQUAMOUS NEOPLASIA

Remains a priority.

RECOMMENDATION FOR INTESTINAL METAPLASIA

IN THE STOMACH

No longer a priority.

The role of AEI in dysplasia detection in Barrett's esophagus and squamous cancer detection in high risk patients remains a research priority. Guidelines have different positions on the use of AEI. Since the publication of the previous ESGE priorities, 17 studies examining NBI, blue-light imaging (BLI), i-scan, and chromoendoscopy with acetic acid and Lugol's iodine have been published and were analyzed, of which nine were prospective and eight retrospective [39-55]. An additional 19 studies were found on less common techniques including endomicroscopy and the application of computer-assisted diagnosis. The level of evidence of these studies was moderate or low.

NBI showed a higher sensitivity for the diagnosis of esophageal cancer compared with white-light endoscopy (WLE), at $91 \%-92 \%$ vs. $51 \%-69 \%[41,42]$, with higher rates of accurate lesion delineation [41]. A retrospective study showed that NBI and iodine staining were both superior to WLE for the diagnosis of esophageal cancer and precancerous lesions $(P<0.05)$, with the diagnostic accuracy of NBI, iodine staining, and WLE being $92.6 \%, 93.3 \%$, and $67.8 \%$, respectively [45].

In conclusion, these new technologies need to be standardized and validated. Further randomized studies and a cost-analysis study need to be conducted to evaluate their benefit. Scientific societies will have a pivotal role in implementing these technologies once their role is established by high quality research trials.

Regarding the role of AEI in gastric precancerous conditions, three systematic reviews were performed prior to 2015 that found a high accuracy for NBI for the diagnosis of IM and dysplasia, although there was less evidence for other technologies [56-58]. Since 2015, 21 studies have focused on this research question ( 3 RCTs and 13 cross-sectional studies with prospective recruitment, with 13 evaluating $\mathrm{NBI}$ and $6 \mathrm{BLI})$.

Two RCTs ( 1 with NBI and 1 with BLI) showed an advantage of these technologies over WLE in the diagnosis of IM and in the detection of early gastric cancer in patients under surveillance $[59,60]$. NBI and BLI have been shown to have a high diagnostic accuracy and are useful for the detection and staging of gastric premalignant conditions and in patient surveillance, at least in expert hands. A scale for endoscopic staging of gastric IM (Endoscopic Grading of Gastric Intestinal Metaplasia [EGGIM]) 
has also been developed and validated, showing high accuracy for IM endoscopic diagnosis [61-63].

There is a need for standardization of patterns and evaluation of the diagnostic yield of AEI in less experienced hands, but it is clear that NBI and BLI increase the accuracy of endoscopic diagnosis and should be used by trained endoscopists using validated classifications, as suggested in the ESGE guidelines $[4,15]$.

\section{Can training modules improve image interpret- ation and lesion recognition for endoscopists?}

\section{RECOMMENDATION}

Remains a priority.

Even if AEl shows an advantage in expert hands, it is not clear how to become an expert in endoscopic diagnosis. Since 2015 , only four studies have evaluated the impact of training on image interpretation. An RCT evaluated the effect of an e-learning training program with video lectures and self-exercises with immediate feedback, and showed an increase in accuracy of $7.4 \%$ in the e-learning group (for differentiating cancerous and noncancerous lesions) [64]. A post-hoc analysis of this RCT showed a greater benefit for depressed and small lesions [65]. A retrospective study also showed that even non-structured training improved the early gastric cancer detection rate [66]. Therefore, only one RCT showed the benefit of a particular e-learning program for the characterization of dysplastic/neoplastic lesions, but there are no studies evaluating training programs for gastric precancerous conditions.

Data related to training in the use of image-enhanced endoscopy in the detection of Barrett's neoplasia are scanty. A single study evaluated the impact of a web-based platform in training endoscopists in the use of acetic acid-enhanced detection of Barrett's neoplasia [67]. They reported a significant improvement in the performance of endoscopists when trained with carefully selected endoscopic images and videos using a webbased platform. Similarly, another recent study using another web-based platform demonstrated a significant improvement in Barrett's neoplasia detection, as well as delineation [68].

Further work is needed to standardize the training structures and demonstrate the impact of these training interventions during real-time endoscopy and clinically meaningful impacts.

\section{Lower gastrointestinal endoscopy}

\section{What is the optimal surveillance of patients following colonoscopic polypectomy?}

\section{RECOMMENDATION}

No longer a priority.

Since the publication of the previous ESGE research priorities, multiple studies have addressed the question of the optimal surveillance of patients following colonoscopic polyp- ectomy. The guidance for the optimal surveillance strategy following polypectomy has recently been radically updated by the British Society of Gastroenterology (BSG), with an emphasis toward reducing the number of patients entering into surveillance programs and prolonging the surveillance interval [69]. Most recently, the ESGE has introduced an update for postpolypectomy colonoscopy surveillance, which differs from the BSG guidelines, but again aims to reduce the need for surveillance [5]. Therefore, the question of the surveillance interval following polypectomy has been successfully addressed.

\section{Can surveillance interval be adjusted depending on both patient factors and the quality of the endoscopy?}

\section{RECOMMENDATION}

Remains a priority.

The surveillance intervals for patients with family history of colorectal cancer, those with sessile serrated polyps (SSPs), and those with (previous) colitis or colectomy following colon cancer have not been defined in recent years.

It has been questioned whether surveillance intervals could be adjusted dependent on both patient factors and the quality of the colonoscopy. Attempts have been made to identify patient factors which could affect surveillance intervals, with some success [70]. It has been established that the risk of post-colonoscopy cancer is not the same for all endoscopists, and those with the highest adenoma detection rates (ADRs) have the lowest rates of post-colonoscopy cancer [71].

Bowel cleansing is a procedure-related issue, with poorer cleansing negatively affecting ADR and the occurrence of post-colonoscopy cancer [72]. The standard of care is to rescope patients with inadequate preparation, although this is not always adhered to [73]. It is unclear whether differentiation of surveillance intervals based on excellent, good, and adequate preparation is of benefit, with a published suggestion that there is no difference in adenoma detection between patients with intermediate and high quality preparation [74].

Currently there is insufficient evidence to recommend personalizing surveillance intervals based on either patient factors or the quality of endoscopy and therefore this remains a priority.

\section{What is the importance of sessile serrated lesions?}

\section{RECOMMENDATION}

Redefine.

What is the best technique for detection, resection, and surveillance of sessile serrated polyps?

The BSG provided a position statement on serrated lesions in the colon and rectum discussing: the premalignant potential of serrated lesions; the detection and resection of serrated 
lesions; surveillance strategies after detection of serrated lesions; serrated polyposis syndrome (including surgery); and serrated lesions in colitis [75]. The previous question relating to the importance of SSPs has been addressed and, although guidance relating to the detection, resection, and surveillance of SSPs has been issued, this statement is based more on expert opinions rather than good evidence. We have therefore redefined the priority to focus on identifying the best technique for detection, resection, and surveillance of SSPs.

\section{Can further polyp characterization (sessile serrated lesions, number of polyps, and size of polyps) be a better predictor of interval cancer rates than adenoma detection rate?}

\section{RECOMMENDATION}

Remains a priority.

The best predictors of post-colonoscopy cancer rate (sessile serrated lesions, number of polyps, etc.) are still not well understood and research into the question of the best predictors of post-colonoscopy cancer is of the utmost importance. Most studies have only focused on the ADR and factors influencing the ADR. Therefore, the question of post-colonoscopy cancer rate in respect to the ADR has been satisfactorily addressed, but the impact of other polyp factors, such as the SSP detection rate, polyp detection rate, size of polyps, and type of polyps, among others, has not been sufficiently addressed, and therefore this remains a priority.

5 What are the risks and benefits of leaving smaller polyps in place in older patients? Is it possible to define an age cutoff where the risks exceed the benefits?

RECOMMENDATION

Remains a priority.

The risks and benefits of leaving smaller polyps in place in older patients is unclear, and the question has been asked as to whether it is possible to define an age cutoff where the risks exceed the benefits. Polyps do recur in older patients, possibly at a more rapid rate than in younger patients (35\% vs. $19 \%$ within 3 years) [76]. However, the adverse impact of polypectomyrelated complications in older patients is likely to be more serious than in younger patients [77].

Whilst it is established that large polyps $>1 \mathrm{~cm}$ in size carry a significant risk of harboring cancer, the absolute risk from diminutive polyps is less clear, with a very large prospective study suggesting that, among 36000 polyps $<5 \mathrm{~mm}$ and 6000 polyps $6-9 \mathrm{~mm}$ in size, no cancers were found [78]. Therefore, the risk of cancer in small polyps is extremely low and the benefits of resection are almost entirely based on preventing later transformation into cancer. In older patients with a limited life expectancy the risk of removal may outweigh any benefits.
Unfortunately, the rate of cancerous transformation is unclear. The only available information comes from a very old study from 1987, which examined non-resected polyps of $10 \mathrm{~mm}$ or more in size over time. It suggested that, over a 6-year period, the cumulative risks of malignant transformation at 5, 10, and 20 years were $2.5 \%, 8 \%$, and $24 \%$, respectively [79].

Whilst it is established that polypectomy during colonoscopy reduces the risk of cancer [80], the benefit may come largely from the resection of larger, high risk polyps regardless of a patient's age. However, this has to be balanced against the individual patient's risk. Older patient populations are more heterogeneous, with increasing co-morbidities, and the risk/ benefit of polypectomy cannot be assessed on age only.

This is an area where research is needed. With an aging population, guidance on how to manage diminutive polyps in older patients is urgently required.

\section{Small-bowel endoscopy}

\section{What is the optimal imaging modality for the small bowel?}

\section{RECOMMENDATION}

Redefine.

How can we better stratify small-bowel investigations for patients with small-bowel inflammation and tumors?

Small-bowel investigations for occult and overt bleeding have been addressed elsewhere, hence the focus of this research priority statement should be on non-bleeding indications for small-bowel investigations. These include Crohn's disease (CD), small-bowel tumors, familial polyposis syndromes, and celiac disease.

\section{Crohn's disease}

Since 2016, a number of systematic reviews and meta-analyses aiming to establish the best imaging modality to investigate the small bowel for the evaluation of CD have been published.

Kopylov et al. published a meta-analysis with the aim of comparing the diagnostic yields of video capsule endoscopy (VCE), magnetic resonance enteroclysis, and small-intestinal contrast ultrasound (SICUS) in the detection of active smallbowel inflammation in patients with suspected and/or established CD, and in the monitoring of the disease [81]. VCE showed a similar diagnostic yield to that of magnetic resonance enteroclysis (odds ratio [OR] 1.17, 95\% confidence interval $[\mathrm{Cl}]$ $0.83-1.67$ ) and SICUS (OR 0.88; $95 \% \mathrm{CI} 0.51-1.53$ ) in the detection of active small-bowel CD.

A systematic review and meta-analysis by Yung et al. compared the accuracy of diagnostic yield for VCE, magnetic resonance enteroclysis, and ultrasound in order to evaluate the correct diagnostic approach to detect postoperative recurrence in CD. The sensitivity, specificity, diagnostic odds ratio (DOR), and area under the curve (AUC) for VCE were $100 \%$ (95\%Cl $91 \%$ $100 \%), 69 \%$ (95\% Cl 52\%-83\%), 30.8 (95\% Cl 6.9-138), and 0.94 , respectively. The sensitivity, specificity, DOR, and AUC 
for magnetic resonance enteroclysis were $97 \%(95 \% \mathrm{Cl} 89 \%-$ $100 \%$ ), 84\% (95\%Cl 62\%-96\%), 129.5 (95\%Cl 16.4-1024.7), and 0.98 , respectively. Ultrasound showed a sensitivity, specificity, DOR, and AUC of $89 \%(95 \% \mathrm{Cl} 85 \%-92 \%), 86 \%(95 \% \mathrm{Cl}$ $78 \%-93 \%), 42.3(95 \% \mathrm{Cl} 18.6-96.0)$, and 0.93 , respectively [82].

The role of endoscopic imaging modalities in the diagnosis, monitoring, and evaluation of treatment response (i.e. mucosal healing) in CD needs to be further explored.

\section{Small-bowel tumors}

The role of imaging modalities for investigating small-bowel tumors is poorly evaluated, particularly in relation to tumor subgroups. Manguso et al. reviewed a database of 85 patients with primary small-bowel NET [83]. The sensitivities for NET detection were $59.7 \%, 54 \%, 56 \%$, and $88.1 \%$ for computed tomography (CT), magnetic resonance imaging (MRI), somatostatin receptor imaging (SRI), and double-balloon enteroscopy (DBE), respectively. DBE was significantly more accurate for primary NET diagnosis than $C T$, MRI, or SRI $(P=0.004, P=0.007$, and $P=0.01$, respectively). When comparing DBE to radiological tests, DBE was recently demonstrated to have a higher overall accuracy for the detection of small-intestinal tumors when compared with multidetector CT: $92.0 \%(n=81 / 88)$ vs. $75 \%$ ( $n=66 / 88) ; P<0.01$ [84].

In conclusion, small-bowel tumors represent a rare condition. Their low incidence makes it difficult to perform large studies. There is a requirement for multicenter trials to improve the current knowledge. Other small-bowel conditions requiring imaging include polyposis syndromes and celiac disease, but no new trials have been published in the last 5 years.

The choice of small-bowel imaging modality depends on the indications, skills, and availability. In many circumstances, different imaging modalities play a complementary rather than an alternative role. New endoscopic techniques are emerging (i. e. pan-enteric capsule endoscopy, steerable capsule endoscopy, motorized spiral enteroscopy) [85-88]. The roles of such new technologies are unknown and studies evaluating their roles are a priority in the field of small-bowel disease. The new priority should be redefined to consider how we can better stratify small-bowel investigations for patients with small-bowel inflammation and tumors.

\section{Should we perform capsule endoscopy or deep enteroscopy?}

\section{RECOMMENDATION}

No longer a priority.

Several recent investigators have compared VCE and DBE as modalities to investigate the small bowel [89-93]. Zhang et al. prospectively compared VCE and DBE demonstrating comparable diagnostic yields [89]. Brito et al. performed a recent meta-analysis comparing the two modalities for small-bowel bleeding [93]; 17 studies were included (1477 lesions), with VCE detecting $58.5 \%$ of lesions and DBE $41.5 \%$. The sensitivity of DBE was $84 \%$ and specificity was $92 \%$. Performing DBE after VCE increased the diagnostic yield of vascular lesions by $7 \%$, from $83 \%$ to $90 \%$. Performing VCE before DBE helps direct the insertion route at DBE and improves diagnostic yields [94]. This has been included in both the ESGE technical review and, more recently, in the ESGE quality improvement initiative [12,95]. Based on this information, this is no longer a research priority.

\section{How can capsule endoscopy be used therapeutically?}

\section{RECOMMENDATION}

Remains a priority.

Several VCE subtypes have been developed to obtain biopsies and for clip placement, along with therapeutic VCE for the treatment of Gl bleeding [96-100]. Despite these technical innovations, no prototypes exist for clinical use. The labor intensity and weight of the external magnet has limited the use of externally controlled steerable capsules [101,102]. Whilst the Ankon capsule (motorized VCE), which uses a magnetic field generated by an external industrial robot, has allowed steerability, this has not yet extended beyond the stomach $[103,104]$. Further innovation is required to see these developments transform into clinical use before this can be prioritized as clinical research.

\section{How should we investigate occult or acute gastrointestinal bleeding following normal upper and lower gastrointestinal endoscopy?}

\section{RECOMMENDATION}

No longer a priority.

For occult bleeding, two systematic reviews, three prospective studies, and 12 retrospective studies have demonstrated a high yield for VCE in patients with iron deficiency anemia [105, $106]$, with a pooled diagnostic yield of $47 \%$. The yield is increased in older patients $[107,108]$ and those with a low hemoglobin [109], although significant pathology can also be found in young patients [110]. Comparisons of VCE and DBE have shown similar yields of pathology [89]. Comparisons of VCE with CT enteroclysis have suggested that VCE is superior to $C T$ enteroclysis when patients with iron deficiency anemia are included $[111,112]$.

For overt bleeding, recent studies have suggested that early VCE, within 48 hours, had a high diagnostic yield, leading to a higher therapeutic intervention rate and shorter hospital stay than when it was delayed to over 48 hours [113-115]. Recent evidence has reinforced the importance of performing VCE before DBE, with a higher diagnostic yield $[116,117]$. Enteroscopy was found to be superior to CT angiography in patients with overt bleeding [118]. In mixed overt and occult bleeding, the combined sensitivity of VCE and CT enteroclysis is greater than either technique alone [112]. 
This supports the notion that there is no single optimal diagnostic modality to explore the small bowel. Despite the heterogeneity of the data, there are enough studies suggesting the use of VCE in the context of iron deficiency anemia when bidirectional endoscopies have been negative. Furthermore, VCE has been adopted across Europe and is the accepted modality to be used for investigation of the small bowel after negative bidirectional endoscopies. For this reason, this should no longer be a priority.

\section{Can we develop automatic reading analysis algorithms?}

RECOMMENDATION

Redefine.

Can automated reading algorithms be safely introduced into clinical practice?

A recent meta-analysis evaluated the sensitivity, specificity, and DOR of the Suspected Blood Indicator (SBI; a tool available in RAPID Reader software, Medtronic, USA) for the detection of potentially bleeding lesions and/or active GI bleeding [119]. Overall, the sensitivity, specificity, and DOR were 0.553 , $0.578,12.354$, respectively; however, the sensitivity, specificity, and DOR for active bleeding were 0.988, 0.646, and 229.89 , respectively. This confirmed the limited sensitivity of $\mathrm{SBI}$ overall, but the very high sensitivity in cases with active GI bleeding.

In the latest version of one of the VCE systems, the RAPID Reader software has been incorporated, and it was found to be able to automatically select the 100 images that mostly likely contained abnormalities. The concordance of findings between the "TOP 100" selection and the standard reading was evaluated, in a retrospective study published by Arieira et al., in 97 consecutive patients presenting with suspected small-bowel bleeding [120]. The TOP 100 identified all sites of active bleeding $(n=9)$, as well as the vast majority of significant lesions $(n=$ $81 / 97 ; 83.5 \%$ ). This sensitivity for the TOP 100 suggests that it cannot entirely replace standard video reading; however, it might be used for preview reading.

Similarly, a novel EndoCapsule software algorithm (Omni Mode; Olympus) was recently developed with the aim of removing duplicate images without losing accuracy in lesion detection. The software was tested in a prospective multicenter study of 315 patients with an indication for VCE. The sensitivity of Omni Mode was 0.89 for clinically significant lesions. On comparing the miss rate of the standard mode and the Omni Mode, the standard mode reading was associated with an accuracy of 0.70 , whereas the accuracy of the Omni Mode reading was 0.75 , without significant differences between either reading mode. The use of the Omni Mode was significantly faster $(P<$ 0.001 ) than standard mode (42.5 minutes), with an average saving time of 24.6 minutes $(95 \% \mathrm{Cl} 22.8-26.9)$, equivalent to a $40 \%$ reduction in reading time [121].
In parallel to the development of these software programs, $\mathrm{Al}$ is entering into the field of digestive endoscopy. Tsuboi et al. tested a convolutional neural network (CNN) Al system to automatically detect small-bowel angioectasia in VCE images [122]. The AUC for the detection of angioectasia was 0.998 . The sensitivity, specificity, positive and negative predictive values of the CNN-based system were $98.8 \%, 98.4 \%, 75.4 \%$, and $99.9 \%$, respectively. Similarly, Leenhardt et al. developed a CNN-based algorithm that showed a $100 \%$ sensitivity, a $96 \%$ specificity, a $96 \%$ positive predictive value, and a $100 \%$ negative predictive value for the detection of angioectasia, with an optimal reproducibility and a reading process time for an entire small-bowel VCE of 39 minutes [123]. The "Deep CNN" system was also trained to recognize blood and was compared to the SBI (RAPID Reader Software) [124]. The AUC for the detection of blood content was 0.9998 . The sensitivity, specificity, and accuracy of the CNN-based algorithm were $96.63 \%$, 99.96\%, and $99.89 \%$, respectively, which were significantly higher than those of the SBI (76.92\%, 99.82\%, and 99.35\%, respectively). The CNN system was proven to be extremely fast, allowing 10208 test images to be evaluated in 250 seconds.

Most of the systems are still in a development phase that does not yet allow the use of the technology in clinical practice. Ankon Technologies (Shanghai, China) recently developed a CNN-based algorithm that is currently in the process of being embedded in the NaviCam Engine reading support platform, which will work together with their already available NaviCam small-bowel capsule system. To our knowledge, this will be the first VCE system to use a deep learning algorithm for routine clinical use. This CNN-based algorithm was evaluated by Ding et al. and showed a per-patient and per-lesion sensitivity for the detection of small-bowel abnormalities of $99.88 \%(95 \% \mathrm{Cl}$ 99.67-99.96) and $99.90 \%(95 \% \mathrm{Cl} 99.74-99.97)$, respectively [125]. The sensitivities of conventional reading were $74.57 \%$ (95\% Cl 73.05-76.03) and $76.89 \%(95 \% \mathrm{Cl} 75.58-78.15)$ in the per-patient and per-lesion analyses, respectively. The mean (standard deviation) reading time was 96.6 (22.53) minutes by conventional reading and 5.9 (2.23) minutes by CNN-based auxiliary reading $(P<0.001)$.

The CNN architectures have been developed and trained in order to recognize ulcers and/or erosions, also with a $92 \%-95 \%$ accuracy, a $91 \%-96 \%$ sensitivity, and a $92 \%-96 \%$ specificity [126-128]. Excellent results were also reported by Klang et al. who described a CNN algorithm trained for patients with CD [129]. The system showed an AUC of 0.99, with an accuracy ranging from $95.4 \%$ to $96.7 \%$ in detecting ulcers in randomly split images.

CNN-based methods have been evaluated in other less frequent small-bowel disorders investigated by VCE. When trained to distinguish celiac disease patients from controls, the CNN achieved a $100 \%$ sensitivity and specificity, also being able to furnish quantitative measurement of the pathology and its degree of severity [130]. Polyp recognition was also evaluated with an accuracy of $98 \%, 99.5 \%, 99 \%$, and $95.5 \%$, for the detection of polyps, bubbles, turbid images, and clear images, respectively; the average overall recognition accuracy was $98 \%$ [131]. Similarly, another novel deep CNN system, able to detect 
protruding lesions, showed an AUC of 0.911 (95\% Cl $0.9069-$ $0.9155)$, with a sensitivity and specificity of $90.7 \%(95 \% \mathrm{Cl}$ $90.0 \%-91.4 \%)$ and $79.8 \%(95 \% \mathrm{Cl} 79.0 \%-80.6 \%)$, respectively [132]. The system was shown to properly classify polyps, nodules, epithelial tumors, submucosal tumors, and venous structures, with sensitivities of $86.5 \%, 92.0 \%, 95.8 \%, 77.0 \%$, and $94.4 \%$, respectively. In individual patient analysis $(n=73)$, the detection rate of protruding lesions was $98.6 \%$.

In conclusion, during the next decade, computerized medicine including $\mathrm{Al}$ will rapidly expand. Most of the current data come from prototype systems and from images and videos from stock library. It seems that the concept of automated reading algorithms has been proven, so the question should be redefined to assess whether automated reading algorithms can be safely introduced into clinical practice.

\section{Hepatopancreatobiliary endoscopy - ERCP} 1 What is the optimal approach to access the biliary tree in patients with altered anatomy?

\section{RECOMMENDATION}

Remains a priority.

The different approaches to accessing the biliary tree in patients with altered anatomy have been included in ESGE guidelines, based on low quality evidence and weak recommendations [133-135]. Most of the studies have assessed different techniques, rather than comparing them in prospective studies or meta-analyses/systematic reviews.

Endoscopic retrograde cholangiopancreatography (ERCP) after Billroth II gastrectomy is challenging, with a reported incidence of perforation of $2.7 \%$. Biliopancreatic cannulation and sphincterotomy has been reported to be successful with sideand forward-viewing endoscopes in $80 \%$ and $83 \%$ of patients, respectively. Cannulation using the side-viewing duodenoscope offers better visualization of the papilla and the elevator assists in the correct orientation of the catheters. For these reasons, a side-viewing duodenoscope should be the approach of choice for ERCP in Billroth II patients and forward-viewing endoscopes should only be used after a failed attempt with a duodenoscope. Prospective data comparing these two approaches are still lacking. Balloon-assisted enteroscopy can increase the success rate of duodenal stump intubation in Billroth II patients. However, the therapeutic role of balloon enteroscopeassisted ERCP is limited because of the forward view, small operative channel, lack of elevator, and the absence of ERCPdedicated catheters [136-138]. This question therefore remains a priority.

\section{Where is precut indicated and safe?}

\section{RECOMMENDATION}

No longer a priority.
Precut is indicated when biliary cannulation fails, as an alternative to repeated multiple attempts and the double-guidewire cannulation technique. Precut can be performed using two different techniques: conventional precut and fistulotomy. The first technique is usually defined as the use of a needle-knife to perform a stepwise incision of the mucosa starting at the upper margin of the papillary orifice and cutting in the direction of the bile duct until the underlying biliary sphincter is visualized. The second technique is usually defined as the use of a needleknife to perform a stepwise incision of the mucosa starting directly over the roof of the papilla and followed by an upward or downward cut until the underlying biliary sphincter is visualized. The goal of the latter technique is to avoid thermal injury to the pancreatic orifice and therefore, theoretically, reduce the risk of post-ERCP pancreatitis.

Several meta-analyses and systematic reviews have been published (the last two in 2018) addressing the indications, safety, and efficacy of precut papillotomy [133,139-143]. On pooled analyses, fistulotomy and early precut significantly decrease the risks of post-ERCP pancreatitis compared with conventional precut and precut performed after multiple cannulation attempts. This issue is no longer a research priority.

\section{What are the roles for MRCP, ERCP, and EUS?}

\section{RECOMMENDATION}

No longer a priority.

There have been a significant number of studies including systematic reviews and meta-analyses published so far on the roles for magnetic resonance cholangiopancreatography (MRCP), ERCP, and endoscopic ultrasound (EUS) [16,31, 144160]. The role of these modalities has been extensively discussed in various guidelines, which have been routinely adopted in clinical practice. ESGE has also published performance measures for ERCP and EUS. This topic is therefore no longer a research priority.

\section{Hepatopancreatobiliary endoscopy - EUS \\ 1 How do we optimally diagnose and manage cystic pancreatic tumors?}

\section{RECOMMENDATION}

No longer a priority.

Within the last 5 years, a large number of studies have been published addressing the topic of pancreatic cystic neoplasm, with most of these being retrospective large series and metaanalyses. The American Gastroenterological Association (AGA), International Association of Pancreatology (IAP), and European study group on Cystic Tumours of the Pancreas have each published guidelines on the management of different types of pancreatic cystic neoplasm [161-163]. Moreover, precise guidance 
on the absolute and relative indications for surgery have been identified.

The role of EUS has been defined in the evaluation of mural nodules and pancreatic duct dilation, with both features being suggestive of high risk neoplasia. Contrast-enhanced EUS has been effective in enhancing nodules, with high positive predictive value [164]. The diagnosis and management of cystic pancreatic tumors is therefore no longer a research priority. However, in terms of the EUS-guided acquisition of cystic fluid or tissue, fine-needle biopsy or more recently through-the-needle biopsy forceps are promising new tools and need to be further evaluated in large prospective studies [165].

\section{How do we improve non-invasive diagnostic methods (e.g. contrast-enhanced endoscopic ultrasonography, 3D reconstruction) for the differential diagnosis of pancreatic cancer and inflammatory diseases?}

\section{RECOMMENDATION}

Remains a priority.

ESGE guidelines recommend performing EUS-guided sampling as the first-line procedure when a pathological diagnosis of pancreatic pathology is required [166]. There has been remarkable progress in the field of less invasive diagnostic methods like EUS elastography and contrast-enhanced imaging [167-170]. Although the evidence from prospective studies looks promising, it is still not enough to change practice. Albased interpretation of EUS and elastography has shown promising results, but is still a research tool [171]. This area remains an active research priority.

\section{Cross-cutting priorities}

\section{How do we define the interface between endotherapy and gastrointestinal surgery?}

\section{RECOMMENDATION}

Redefine.

How can we explore the interface between endotherapy and surgery to identify the conditions and patients that are best treated by surgery, endotherapy, or a combination of both? emerged, proving the feasibility and safety of these techniques in expert hands, but data are needed on the generalization of these techniques and also for direct comparisons of the endoscopic techniques with surgery. It remains an important research priority to compare those different approaches in prospective trials to assess which option offers the better benefit/ risk ratio.

Peroral endoscopic myotomy (POEM) has been proven to be a valuable option in treating achalasia, but it has been shown to result in a high rate of gastroesophageal reflux disease (GERD) $[172,173]$. It was recently compared with laparoscopic Heller's myotomy in a prospective multicenter RCT and was proven to be as effective as surgery but with an apparent higher rate of GERD [173]. Nevertheless, the long-term impact of this GERD should be evaluated to define whether POEM or Heller's myotomy should be proposed as the first-line treatment depending on the patient's age and co-morbidities.

Recently, the principles of POEM have led to the development of third-space endoscopy or submucosal endoscopy as a new interface between endoscopy and surgery. This approach has also been used to treat different motility disorders, such as gastroparesis [174] and non-achalasia esophageal motility disorders [175], Zenker's diverticulum [176], and submucosal tumors with techniques like submucosal tunneling endoscopic resection [177] and combined endoscopic and surgical approaches [178]. These techniques have been reported in noncomparative studies and it is now necessary to compare them to the corresponding surgery or other endoscopic treatment modalities.

The treatment of obesity is becoming increasingly important owing to the global increase in its incidence. Endoscopy has two roles in this pathology, as a primary treatment with an endoscopic gastroplasty procedure [179-181] and as a means of managing surgical complications [182-184]. The place of endoscopy and surgery in obesity treatment is still based on low levels of evidence, and prospective protocols with comparative design are needed to determine the most appropriate approaches, according to the severity of obesity, the type of complication it is causing, or the metabolic profile of the patient. Metabolic endoscopy, for example with duodenal mucosal resurfacing, should also be compared with the different surgical concepts [185]. This question should therefore be redefined to address how we can explore the interface between endotherapy and surgery and identify the conditions and patients that are best treated by surgery, endotherapy, or a combination of both.
The rapid development of various endoscopic techniques in the last decade has resulted in a major paradigm shift. A large number of conditions, which were conventionally treated by radical surgery, are now being treated endoscopically. Early GI neoplasia, achalasia, obesity, GI leaks, and fistulas, among others are examples of conditions that previously fell under the surgical domain, but are now being treated endoscopically in tertiary centers by select experts. Data on the efficacy and safety of these new endoscopic techniques have rapidly 
- Table1 Decisions made on review of the previous research priorities.

\begin{tabular}{|c|c|c|c|}
\hline Research priority & Remains & Redefined & Removed \\
\hline \multicolumn{4}{|l|}{ Generic priorities } \\
\hline How do we define the correct surveillance interval following initial endoscopic diagnosis & & $x$ & \\
\hline How do we correctly utilize advanced endoscopic imaging? & & $x$ & \\
\hline What are the best markers of endoscopy quality? & & $\mathrm{x}$ & \\
\hline \multicolumn{4}{|l|}{ Upper gastrointestinal endoscopy } \\
\hline What is the correct surveillance strategy for atrophic gastritis and metaplastic gastritis? & $x$ & & \\
\hline What is the correct surveillance strategy for Barrett's esophagus? & $\mathrm{x}$ & & \\
\hline When can anticoagulant medication be restarted following gastrointestinal bleeding? & $x$ & & \\
\hline $\begin{array}{l}\text { What is the role of advanced imaging in dysplasia detection in Barrett's esophagus, } \\
\text { squamous cancer detection in high risk patients or intestinal metaplasia in the stomach? }\end{array}$ & $\begin{array}{l}\text { X (Barrett's and } \\
\text { squamous neo- } \\
\text { plasia) }\end{array}$ & & $\begin{array}{l}X \text { (Intestinal } \\
\text { metaplasia in } \\
\text { the stomach) }\end{array}$ \\
\hline $\begin{array}{l}\text { Can training modules improve image interpretation and lesion recognition for endos- } \\
\text { copists }\end{array}$ & $\mathrm{x}$ & & \\
\hline
\end{tabular}

Lower gastrointestinal endoscopy

What is the optimal surveillance of patients following colonoscopic polypectomy? What is the importance of sessile serrated polyps?

Can further polyp characterization (sessile serrated lesions, number of polyps, and size of polyps) be a better predictor of interval cancer rates than adenoma detection rate?

What are the risks and benefits of leaving smaller polyps in place in older persons? Is it possible to define an age cutoff where the risks exceed the benefits?

Can surveillance interval be adjusted depending upon both patient factors and the quality of the endoscopy?

\section{Small-bowel endoscopy}

How should we investigate occult or acute gastrointestinal bleeding following normal upper and lower gastrointestinal endoscopy?

What is the optimal imaging modality for small bowel?

How can capsule endoscopy be used therapeutically?

Should we perform capsule endoscopy or deep enteroscopy?

Can we develop automatic reading analysis algorithms?

\section{Hepatopancreaticobiliary endoscopy - EUS}

How do we optimally diagnose and manage cystic pancreatic tumors?

How do we improve non-invasive diagnostic methods (e. g. contrast-enhanced endoscopic ultrasonography, $3 \mathrm{D}$ reconstruction) for differential diagnosis of pancreatic cancer and inflammatory diseases?

\section{Hepatopancreaticobiliary endoscopy - ERCP}

What are the roles for magnetic resonance cholangiopancreatography, endoscopic retrograde cholangiopancreatography, and endoscopic ultrasonography?

What is the optimal approach to access the biliary tree in patients with altered anatomy?

Where is precut indicated and safe?

$x$

$x$

$x$

\section{Other cross-cutting themes/questions}

How do we define the interface between endotherapy and gastrointestinal surgery?

Can we better understand the prevalence and natural history of diseases diagnosed and treated by gastrointestinal endoscopy, in particular neoplasia? 
$>$ Table 1 (Continuation)

\section{Research priority}

How do we validate and establish the clinical application of scoring and diagnostic tools for gastrointestinal endoscopy?

EUS, endoscopic ultrasound; ERCP endoscopic retrograde cholangiopancreatography.

- Table 2 The revised research priorities.

\section{Generic priorities}

What is the impact of endoscopic surveillance on incidence and disease-specific survival?

How can advanced endoscopic imaging be implemented to change clinical practice?

How can we implement and monitor adherence to the KQIs and quantify the long-term benefits of such implementation, as well as developing and validating the patient experience-related KQIs?

\section{Upper gastrointestinal endoscopy}

What is the correct surveillance strategy for atrophic gastritis and metaplastic gastritis?

What is the correct surveillance strategy for Barrett's esophagus?

When can anticoagulant medication be restarted following gastrointestinal bleeding?

What is the role of advanced imaging in the detection of dysplasia in Barrett's esophagus and squamous esophagus in high risk patients?

Can training modules improve image interpretation and lesion recognition for endoscopists?

\section{Lower gastrointestinal endoscopy}

Can surveillance interval be adjusted depending on both patient factors and the quality of the endoscopy?

What is the best technique for detection, resection, and surveillance of sessile serrated polyps?

Can further polyp characterization (sessile serrated lesions, number of polyps, and size of polyps) be a better predictor of interval cancer rates than adenoma detection rate?

What are the risks and benefits of leaving smaller polyps in place in older patients? Is it possible to define an age cutoff where the risks exceed the benefits?

\section{Small-bowel endoscopy}

How can we better stratify small-bowel investigations for patients with small-bowel inflammation and tumors?

How can capsule endoscopy be used therapeutically?

Can automated reading algorithms be safely introduced into clinical practice?

Hepatopancreaticobiliary endoscopy - ERCP

What is the optimal approach to access the biliary tree in patients with altered anatomy?

Hepatopancreaticobiliary endoscopy - EUS

How do we improve non-invasive diagnostic methods (e. g. contrast-enhanced endoscopic ultrasonography, 3 D reconstruction) for the differential diagnosis of pancreatic cancer and inflammatory diseases?

\section{Other cross-cutting themes}

How can we explore the interface between endotherapy and surgery to identify the conditions and patients that are best treated by surgery, endotherapy, or a combination of both?

How do we validate and establish the clinical application of scoring and diagnostic tools for gastrointestinal endoscopy?

KQI, key quality indicator; ERCP, endoscopic retrograde cholangiopancreatography; EUS, endoscopic ultrasound. 


\section{How do we validate and establish the clinical application of scoring and diagnostic tools for gastrointestinal endoscopy?}

\section{RECOMMENDATION}

Remains a priority.

Currently, we have numerous scores for various pathologies, among which are the prognostic scores for Gl bleeding and for endoscopic resection of GI neoplasia.

There are two scores that deal with technical difficulty or prediction of recurrence after endoscopic mucosal resection (EMR) of colorectal polyps [186-192]. The first score, called the SMSA score, is based on the variables size (S), morphology $(M)$, site $(S)$, and access $(A)$, and has been studied by various groups, who have demonstrated the link between the SMSA score and the outcome of colonic EMR [187-190]. The second score, the Sydney EMR Recurrence Tool (SERT), has been shown to predict post-EMR recurrence [191]. This score has also recently been validated in another study [192]. There are two further scoring systems to predict delayed bleeding following colorectal EMR $[193,194]$, with another study recently validating and optimizing the previous scores [195]. There is also a publication that classifies deep mural injury and perforation risk [196]; however, there are no tools to predict this complication.

In reference to ESD, there are a few studies that have described scoring systems to predict difficulty in resection, obtaining an en bloc resection, perforation, and delayed bleeding [197-199]. None of these have external validation.

It seems that a series of scoring systems have been developed, but they have not become part of routine clinical practice. It therefore remains a priority to validate these existing scoring systems and integrate them into clinical practice.

\section{Can we better understand the prevalence and natural history of diseases diagnosed and treated by gastrointestinal endoscopy, in particular neoplasia?}

\section{RECOMMENDATION}

No longer a priority.

The natural history and prevalence of GI neoplasia and other conditions have been appropriately addressed under the relevant dedicated sections, so this no longer remains an independent priority.

\section{Conclusions}

The previous ESGE research priorities document published in 2016 had 26 research priorities under seven domains. Our review of these priorities has resulted in seven priorities being removed from the list, one priority being partially removed, another seven being redefined to make them more precise, and 11 priorities remaining unchanged ( $\triangleright$ Table 1 ). This has led to the development of a new list of 19 research priorities under seven domains ( $>$ Table 2 ). This is a reflection of a rapid surge in endoscopic research resulting in $27 \%$ of research questions already having been answered and another $27 \%$ of research questions requiring redefinition.

\section{Competing interests}

A. Anderloni has provided consultancy for Boston Scientific (2016 to date), Olympus (2018 to present), and Medtronic (2018-2019). M. Barthet has received a research grant from Boston Scientific (2016 to present). P. Bhandari has received educational event support from Olympus, speaker's fees and grants from Pentax, Medtronic, Boston Scientific, and 3-D Matrix, and is on the advisory board and received a research grant from Fujifilm (all 2017 to present). M. Dinis-Ribeiro has provided consultancy for Medtronic (2020); he is co-Editor-inChief of Endoscopy. R. Haidry has received research funding from Medtronic (2013), Pentax (2013 to present), and Cook Endoscopy (2016 to present). H. Neumann has provided consultancy for Fujifilm, Sonoscope, Boston Scientific, and Medtronic (2019-2020). T. Ponchon has provided consultancy for Olympus, Boston Scientific, Norgine, and Ipsen (2020 to present); his department has received research funding from Olympus and Boston Scientific (2020 to present). A. Repici has received research grants and consultancy fees from Boston Scientific, Fujifilm, Medtronic, and Erbe. P.D. Siersema receives research support from Pentax, The eNose company, Norgine, Motus $\mathrm{Gl}$, and MicroTech; he is Editor-in-Chief of Endoscopy. C. Spada has provided consultancy for Medtronic, AlfaSigma, Norgine, Pentax, and Olympus (2016 to present). P.A. Testoni's department has received meeting sponsorship and trials support from Pentax (2000 to present). E. Albeniz, G. Antonelli, L. Diogo, L. Fuccio, C. Hassan, G. LongcroftWheaton, P. Pimentel-Nunes, M. Pioche, and R. Sidhu declare that they have no conflict of interest.

\section{References}

[1] Rees C], Ngu WS, Regula J et al. European Society of Gastrointestinal Endoscopy - Establishing the key unanswered research questions within gastrointestinal endoscopy. Endoscopy 2016; 48: 884-891

[2] Balshem H, Helfand M, Schünemann HJ et al. GRADE guidelines: 3. Rating the quality of evidence. J Clin Epidemiol 2011; 64: 401-406

[3] Weusten B, Bisschops R, Coron E et al. Endoscopic management of Barrett's esophagus: European Society of Gastrointestinal Endoscopy (ESGE) Position Statement. Endoscopy 2017; 49: 191-198

[4] Pimentel-Nunes P, Libânio D, Marcos-Pinto R et al. Management of epithelial precancerous conditions and lesions in the stomach (MAPS II): European Society of Gastrointestinal Endoscopy (ESGE), European Helicobacter and Microbiota Study Group (EHMSG), European Society of Pathology (ESP), and Sociedade Port. Endoscopy 2019; 51: $365-388$

[5] Hassan C, Antonelli G, Dumonceau JM et al. Post-polypectomy colonoscopy surveillance: European Society of Gastrointestinal Endoscopy (ESGE) Guideline - Update 2020. Endoscopy 2020; 52: 687700

[6] Hassan C, Wysocki PT, Fuccio L et al. Endoscopic surveillance after surgical or endoscopic resection for colorectal cancer: European Society of Gastrointestinal Endoscopy (ESGE) and European Society of Digestive Oncology (ESDO) Guideline. Endoscopy 2019; 51: 266 277 
[7] Atkin W, Wooldrage K, Brenner A et al. Adenoma surveillance and colorectal cancer incidence: a retrospective, multicentre, cohort study. Lancet Oncol 2017; 18: 823-834

[8] Wieszczy P, Kaminski MF, Franczyk R et al. Colorectal cancer incidence and mortality after removal of adenomas during screening colonoscopies. Gastroenterology 2020; 158: 875-883.e5

[9] He X, Hang D, Wu K et al. Long-term risk of colorectal cancer after removal of conventional adenomas and serrated polyps. Gastroenterology 2020; 158: 852-861.e4

[10] Helsingen LM, Vandvik PO, Jodal HC et al. Colorectal cancer screening with faecal immunochemical testing, sigmoidoscopy or colonoscopy: a clinical practice guideline. BMJ 2019; 367: 15515

[11] Jover R, Bretthauer M, Dekker E et al. Rationale and design of the European Polyp Surveillance (EPoS) trials. Endoscopy 2016; 48: 571578

[12] Spada C, McNamara D, Despott EJ et al. Performance measures for small-bowel endoscopy: a European Society of Gastrointestinal Endoscopy (ESGE) Quality Improvement Initiative. Endoscopy 2019; 51: $574-598$

[13] Valori R, Cortas G, de Lange T et al. Performance measures for endoscopy services: a European Society of Gastrointestinal Endoscopy (ESGE) Quality Improvement Initiative. Endoscopy 2018; 50: 1186-1204

[14] Dekker E, Houwen BBSL, Puig I et al. Curriculum for optical diagnosis training in Europe: European Society of Gastrointestinal Endoscopy (ESGE) Position Statement. Endoscopy 2020; 52: 899-923

[15] East JE, Vleugels JL, Roelandt P et al. Advanced endoscopic imaging: European Society of Gastrointestinal Endoscopy (ESGE) Technology Review. Endoscopy 2016; 48: 1029-1045

[16] Bisschops R, East JE, Hassan C et al. Advanced imaging for detection and differentiation of colorectal neoplasia: European Society of Gastrointestinal Endoscopy (ESGE) Guideline - Update 2019. Endoscopy 2019; 51: 1155-1179

[17] Domagk D, Oppong KW, Aabakken L et al. Performance measures for ERCP and endoscopic ultrasound: a European Society of Gastrointestinal Endoscopy (ESGE) Quality Improvement Initiative. Endoscopy 2018; 50: 1116-1127

[18] Kaminski MF, Thomas-Gibson S, Bugajski M et al. Performance measures for lower gastrointestinal endoscopy: a European Society of Gastrointestinal Endoscopy (ESGE) Quality Improvement Initiative. Endoscopy 2017; 49: 378-397

[19] Bisschops R, Areia M, Coron E et al. Performance measures for upper gastrointestinal endoscopy: a European Society of Gastrointestinal Endoscopy (ESGE) Quality Improvement Initiative. Endoscopy 2016; 48: 843-864

[20] Bisschops R, Dekker E, East JE et al. European Society of Gastrointestinal Endoscopy (ESGE) curricula development for postgraduate training in advanced endoscopic procedures: rationale and methodology. Endoscopy 2019; 51: 976-979

[21] Pimentel-Nunes P, Pioche M, Albéniz E et al. Curriculum for endoscopic submucosal dissection training in Europe: European Society of Gastrointestinal Endoscopy (ESGE) Position Statement. Endoscopy 2019; 51: 980-992

[22] Sidhu R, Chetcuti Zammit S, Baltes P et al. Curriculum for smallbowel capsule endoscopy and device-assisted enteroscopy training in Europe: European Society of Gastrointestinal Endoscopy (ESGE) Position Statement. Endoscopy 2020; 52: 669-686

[23] Khan R, Plahouras J, Johnston BC et al. Virtual reality simulation training in endoscopy: a Cochrane review and meta-analysis. Endoscopy 2019; 51: 653-664

[24] Lahner E, Caruana P, D'Ambra G et al. First endoscopic-histologic follow-up in patients with body-predominant atrophic gastritis: when should it be done? Gastrointest Endosc 2001; 53: 443-448
[25] Banks M, Graham D, Jansen M et al. British Society of Gastroenterology guidelines on the diagnosis and management of patients at risk of gastric adenocarcinoma. Gut 2019; 68: 1545-1575

[26] Qumseya B, Sultan S et al. ASGE Standards Of Practice Committee. ASGE guideline on screening and surveillance of Barrett's esophagus. Gastrointest Endosc 2019; 90: 335-359.e2

[27] Shaheen N], Falk GW, lyer PG et al. American College of Gastroenterology. ACG Clinical Guideline: diagnosis and management of Barrett's esophagus. Am J Gastroenterol 2016; 111: 30-51

[28] Ding YE, Li Y, He XK et al. Impact of Barrett's esophagus surveillance on the prognosis of esophageal adenocarcinoma: A meta-analysis. J Dig Dis 2018; 19: 737-744

[29] Codipilly DC, Chandar AK, Singh S et al. The effect of endoscopic surveillance in patients with Barrett's esophagus: a systematic review and meta-analysis. Gastroenterology 2018; 154: 2068-2086. e5

[30] Vennalaganti PR, Kaul V, Wang KK et al. Increased detection of Barrett's esophagus-associated neoplasia using wide-area trans-epithelial sampling: a multicenter, prospective, randomized trial. Gastrointest Endosc 2018; 87: 348-355

[31] Longcroft-Wheaton G, Fogg C, Chedgy F et al. A feasibility trial of Acetic acid-targeted Biopsies versus nontargeted quadrantic biopsies during BArrett's surveillance: the ABBA trial. Endoscopy 2020; 52: $29-36$

[32] Cotton CC, Haidry R, Thrift AP et al. Development of evidence-based surveillance intervals after radiofrequency ablation of Barrett's esophagus. Gastroenterology 2018; 155: 316-326.e6

[33] Valanejad SM, Davis KA, Nisly SA. Outcomes associated with resuming direct oral anticoagulant therapy following admission for a gastrointestinal bleed. Ann Pharmacother 2020; 54: 975-980

[34] Sostres C, Marcén B, Laredo V et al. Risk of rebleeding, vascular events and death after gastrointestinal bleeding in anticoagulant and/or antiplatelet users. Aliment Pharmacol Ther 2019; 50: 919929

[35] Sengupta N, Marshall AL, Jones BA et al. Rebleeding vs thromboembolism after hospitalization for gastrointestinal bleeding in patients on direct oral anticoagulants. Clin Gastroenterol Hepatol 2018; 16: 1893-1900.e2

[36] Oakland K, Desborough MJ, Murphy MF et al. Rebleeding and mortality after lower gastrointestinal bleeding in patients taking antiplatelets or anticoagulants. Clin Gastroenterol Hepatol 2019; 17: 1276-1284.e3

[37] Nagata N, Sakurai T, Moriyasu S et al. Impact of INR monitoring, reversal agent use, heparin bridging, and anticoagulant interruption on rebleeding and thromboembolism in acute gastrointestinal bleeding. PLoS One 2017; 12: e0183423

[38] Patel P, Nigam N, Sengupta N. Resumption of warfarin after hospitalization for lower gastrointestinal bleeding and mortality benefits. J Clin Gastroenterol 2018; 52: 545-550

[39] Kato M, Hayashi Y, Uema R et al. Additional effect of magnifying narrow-band imaging on estimating the invasion depth of superficial esophageal cancer. JGH Open 2019; 4: 178-184

[40] Su HA, Hsiao SW, Hsu YC et al. Superiority of NBI endoscopy to PET/ CT scan in detecting esophageal cancer among head and neck cancer patients: a retrospective cohort analysis. BMC Cancer 2020; 20: 69

[41] Su Z, Wang L, Wei S et al. Clinical diagnostic value of digestive endoscopic narrow-band imaging in early esophageal cancer. Oncol Lett 2019; 17: 5481-5486

[42] Dobashi A, Goda K, Furuhashi H et al. Diagnostic efficacy of dualfocus endoscopy with narrow-band imaging using simplified dyad criteria for superficial esophageal squamous cell carcinoma. J Gastroenterol 2019; 54: 501-510 
[43] Everson MA, Lovat LB, Graham DG et al. Virtual chromoendoscopy by using optical enhancement improves the detection of Barrett's esophagus-associated neoplasia. Gastrointest Endosc 2019; 89: 247-256.e4

[44] Diao W, Huang X, Shen L et al. Diagnostic ability of blue laser imaging combined with magnifying endoscopy for early esophageal cancer. Dig Liver Dis 2018; 50: 1035-1040

[45] Gai W, Jin XF, Du R et al. Efficacy of narrow-band imaging in detecting early esophageal cancer and risk factors for its occurrence. Indian J Gastroenterol 2018; 37: 79-85

[46] Katada C, Tanabe S, Wada T et al. Retrospective assessment of the diagnostic accuracy of the depth of invasion by narrow band imaging magnifying endoscopy in patients with superficial esophageal squamous cell carcinoma. J Gastrointest Cancer 2019; 50: 292-297

[47] Kandiah K, Chedgy FJQ, Subramaniam S et al. International development and validation of a classification system for the identification of Barrett's neoplasia using acetic acid chromoendoscopy: the Portsmouth acetic acid classification (PREDICT). Gut 2018; 67: 2085-2092

[48] Kikuchi D, lizuka T, Hoteya S et al. Vascular density of superficial esophageal squamous cell carcinoma determined by direct observation of resected specimen using narrow band imaging with magnifying endoscopy. Dis Esophagus 2017; 30: 1-5

[49] Fujiyoshi T, Tajika M, Tanaka T et al. Comparative evaluation of new and conventional classifications of magnifying endoscopy with narrow band imaging for invasion depth of superficial esophageal squamous cell carcinoma. Dis Esophagus 2017; 30: 1-8

[50] Lipman G, Bisschops R, Sehgal V et al. Systematic assessment with ISCAN magnification endoscopy and acetic acid improves dysplasia detection in patients with Barrett's esophagus. Endoscopy 2017; 49: $1219-1228$

[51] Pennachi CMPS, Moura DTH, Amorim RBP et al. Lugol's iodine chromoendoscopy versus narrow band image enhanced endoscopy for the detection of esophageal cancer in patients with stenosis secondary to caustic/corrosive agent ingestion. Arq Gastroenterol 2017; 54: 250-254

[52] Nogales O, Caballero-Marcos A, Clemente-Sánchez A et al. Usefulness of non-magnifying narrow band imaging in EVIS EXERA III video systems and high-definition endoscopes to diagnose dysplasia in Barrett's esophagus using the Barrett International NBI Group (BING) classification. Dig Dis Sci 2017; 62: 2840-2846

[53] Tomie A, Dohi O, Yagi N et al. Blue laser imaging-bright improves endoscopic recognition of superficial esophageal squamous cell carcinoma. Gastroenterol Res Pract 2016; 2016: 6140854

[54] Kato M, Goda K, Shimizu Y et al. Image assessment of Barrett's esophagus using the simplified narrow band imaging classification. J Gastroenterol 2017; 52: 466-475

[55] Pascarenco OD, Coroş MF, Pascarenco G et al. A preliminary feasibility study: Narrow-band imaging targeted versus standard white light endoscopy non-targeted biopsies in a surveillance Barrett's population. Dig Liver Dis 2016; 48: 1048-1053

[56] Kikuste I, Marques-Pereira R, Monteiro-Soares M et al. Systematic review of the diagnosis of gastric premalignant conditions and neoplasia with high-resolution endoscopic technologies. Scand I Gastroenterol 2013; 48: 1108-1117

[57] Hu YY, Lian QW, Lin ZH et al. Diagnostic performance of magnifying narrow-band imaging for early gastric cancer: A meta-analysis. World J Gastroenterol 2015; 21: 7884-7894

[58] Wang L, Huang W, Du J et al. Diagnostic yield of the light blue crest sign in gastric intestinal metaplasia: a meta-analysis. PLoS One 2014; 9: e92874

[59] Dohi O, Yagi N, Naito Y et al. Blue laser imaging-bright improves the real-time detection rate of early gastric cancer: a randomized controlled study. Gastrointest Endosc 2019; 89: 47-57
[60] Buxbaum JL, Hormozdi D, Dinis-Ribeiro M et al. Narrow-band imaging versus white light versus mapping biopsy for gastric intestinal metaplasia: a prospective blinded trial. Gastrointest Endosc 2017; 86: 857-865

[61] Castro R, Esposito G, Libânio D et al. A single vial is enough in the absence of endoscopic suspected intestinal metaplasia - less is more! Scand J Gastroenterol 2019; 54: 673-677

[62] Esposito G, Pimentel-Nunes P, Angeletti S et al. Endoscopic grading of gastric intestinal metaplasia (EGGIM): a multicenter validation study. Endoscopy 2019; 51: 515-521

[63] Pimentel-Nunes P, Libânio D, Lage J et al. A multicenter prospective study of the real-time use of narrow-band imaging in the diagnosis of premalignant gastric conditions and lesions. Endoscopy 2016; 48: 723-730

[64] Nakanishi H, Doyama H, Ishikawa $\mathrm{H}$ et al. Evaluation of an e-learning system for diagnosis of gastric lesions using magnifying narrowband imaging: a multicenter randomized controlled study. Endoscopy 2017; 49: 957-967

[65] Ikehara H, Doyama H, Nakanishi $\mathrm{H}$ et al. Analysis of factors related to poor outcome after e-learning training in endoscopic diagnosis of early gastric cancer using magnifying narrow-band imaging. Gastrointest Endosc 2019; 90: 440-447.e1

[66] Zhang Q, Chen ZY, Chen CD et al. Training in early gastric cancer diagnosis improves the detection rate of early gastric cancer: an observational study in China. Medicine (Baltimore) 2015; 94: e384

[67] Chedgy FJQ, Kandiah K, Barr H et al. Development and validation of a training module on the use of acetic acid for the detection of Barrett's neoplasia. Endoscopy 2017; 49: 121-129

[68] Bergman JJGHM, de Groof AJ, Pech O et al. An interactive web-based educational tool improves detection and delineation of Barrett's esophagus-related neoplasia. Gastroenterology 2019; 156: 12991308.e3

[69] Rutter MD, East J, Rees CJ et al. British Society of Gastroenterology/ Association of Coloproctology of Great Britain and Ireland/Public Health England post-polypectomy and post-colorectal cancer resection surveillance guidelines. Gut 2020; 69: 201-223

[70] Atkin W, Brenner A, Martin J et al. The clinical effectiveness of different surveillance strategies to prevent colorectal cancer in people with intermediate-grade colorectal adenomas: a retrospective cohort analysis, and psychological and economic evaluations. Health Technol Assess 2017; 21: 1-536

[71] Kaminski MF, Regula J, Kraszewska E et al. Quality indicators for colonoscopy and the risk of interval cancer. NEJM 2010; 362: 17951803

[72] Kim JS, Kang SH, Moon HS et al. Impact of bowel preparation quality on adenoma identification during colonoscopy and optimal timing of surveillance. Dig Dis Sci 2015; 60: 3092-3099

[73] Butterly LF, Nadel MR, Anderson JC et al. Impact of colonoscopy bowel preparation quality on follow-up interval recommendations for average-risk patients with normal screening colonoscopies: data from the New Hampshire Colonoscopy Registry. J Clin Gastroenterol 2020; 54: 356-364

[74] Clark BT, Rustagi T, Laine L. What level of bowel prep quality requires early repeat colonoscopy: systematic review and meta-analysis of the impact of preparation quality on adenoma detection rate. Am J Gastroenterol 2014; 109: 1714-1724

[75] East JE, Atkin WS, Bateman AC et al. British Society of Gastroenterology position statement on serrated polyps in the colon and rectum. Gut 2017; 66: 1181-1196

[76] Pommergaard HC, Burcharth J, Rosenberg J et al. Advanced age is a risk factor for proximal adenoma recurrence following colonoscopy and polypectomy. Br J Surg 2016; 103: e100-e105 
[77] Hamdani U, Naeem R, Haider F et al. Risk factors for colonoscopic perforation: a population-based study of 80118 cases. World J Gastroenterol 2013; 19: 3596-3601

[78] Ponugoti PL, Cummings OW, Rex DK. Risk of cancer in small and diminutive colorectal polyps. Dig Liver Dis 2017; 49: 34-37

[79] Stryker S], Wolff BG, Culp CE et al. Natural history of untreated coIonic polyps. Gastroenterology 1987; 93: 1009-1013

[80] Kahi C]. Reviewing the evidence that polypectomy prevents cancer. Gastrointest Endosc Clin N Am 2019; 29: 577-585

[81] Kopylov U, Yung DE, Engel T et al. Diagnostic yield of capsule endoscopy versus magnetic resonance enterography and small bowel contrast ultrasound in the evaluation of small bowel Crohn's disease: Systematic review and meta-analysis. Dig Liver Dis 2017; 49: 854-863

[82] Yung DE, Har-Noy O, Tham YS et al. Capsule endoscopy, magnetic resonance enterography, and small bowel ultrasound for evaluation of postoperative recurrence in Crohn's disease: systematic review and meta-analysis. Inflamm Bowel Dis 2017; 24: 93-100

[83] Manguso N, Gangi A, Johnson J et al. The role of pre-operative imaging and double balloon enteroscopy in the surgical management of small bowel neuroendocrine tumors: Is it necessary? J Surg Oncol 2018; 117: 207-212

[84] Ye H, Chen C. Comparison of double-balloon endoscopy and multidetector row computed tomography in diagnosis of small intestinal tumors. Zhejiang Da Xue Xue Bao Yi Xue Ban 2017; 46: 557-562

[85] Leighton JA, Helper DJ, Gralnek IM et al. Comparing diagnostic yield of a novel pan-enteric video capsule endoscope with ileocolonoscopy in patients with active Crohn's disease: a feasibility study. Gastrointest Endosc 2017; 85: 196-205.e1

[86] Eliakim R, Spada C, Lapidus A et al. Evaluation of a new pan-enteric video capsule endoscopy system in patients with suspected or established inflammatory bowel disease - feasibility study. Endosc Int Open 2018; 6: E1235-E1246

[87] Jiang X, Qian YY, Liu X et al. Impact of magnetic steering on gastric transit time of a capsule endoscopy (with video). Gastrointest Endosc 2018; 88: 746-754

[88] Beyna T, Arvanitakis M, Schneider M et al. Motorised spiral enteroscopy: first prospective clinical feasibility study. Gut 2021; 70: 261267

[89] Zhang ZH, Qiu CH, Li Y. Different roles of capsule endoscopy and double-balloon enteroscopy in obscure small intestinal diseases. World J Gastroenterol 2015; 21: 7297-7304

[90] Hermans C, Stronkhorst A, Tjhie-Wensing A et al. Double-balloon endoscopy in overt and occult small bowel bleeding: results, complications, and correlation with prior videocapsule endoscopy in a tertiary referral center. Clin Endosc 2017; 50: 69-75

[91] Maeda Y, Moribata K, Deguchi H et al. Video capsule endoscopy as the initial examination for overt obscure gastrointestinal bleeding can efficiently identify patients who require double-balloon enteroscopy. BMC Gastroenterol 2015; 15: 132

[92] Kakiya Y, Shiba M, Okamoto J et al. A comparison between capsule endoscopy and double balloon enteroscopy using propensity scorematching analysis in patients with previous obscure gastrointestinal bleeding. Scand J Gastroenterol 2017; 52: 306-311

[93] Brito HP, Ribeiro IB, de Moura DTH et al. Video capsule endoscopy vs double-balloon enteroscopy in the diagnosis of small bowel bleeding: A systematic review and meta-analysis. World J Gastrointest Endosc 2018; 10: 400-421

[94] Teshima CW, Kuipers EJ, van Zanten SV et al. Double balloon enteroscopy and capsule endoscopy for obscure gastrointestinal bleeding: an updated meta-analysis. J Gastroenterol Hepatol 2011; 26: 796-801
[95] Rondonotti E, Spada C, Adler S et al. Small-bowel capsule endoscopy and device-assisted enteroscopy for diagnosis and treatment of small-bowel disorders: European Society of Gastrointestinal Endoscopy (ESGE) Technical Review. Endoscopy 2018; 50: 423-446

[96] Simi M, Gerboni G, Menciassi A et al. Magnetic torsion spring mechanism for a wireless biopsy capsule. J Med Devices 2013; 7: 041009

[97] Yim S, Gultepe E, Gracias DH et al. Biopsy using a magnetic capsule endoscope carrying, releasing, and retrieving untethered microgrippers. IEEE Trans Biomed Eng 2014; 61: 513-521

[98] Valdastri P, Quaglia C, Susilo E et al. Wireless therapeutic endoscopic capsule: in vivo experiment. Endoscopy 2008; 40: 979-982

[99] Woods SP, Constandinou TG. Wireless capsule endoscope for targeted drug delivery: mechanics and design considerations. IEEE Trans Biomed Eng 2013; 60: 945-953

[100] Çolak B, Şakalak H, Çavuşoğlu H et al. Novel capsules for potential theranostics of obscure gastrointestinal bleedings. Med Hypotheses 2016; 94: 99-102

[101] Ching HL, Hale MF, Sidhu R et al. Magnetically assisted capsule endoscopy in suspected acute upper $\mathrm{Gl}$ bleeding versus esophagogastroduodenoscopy in detecting focal lesions. Gastrointest Endosc 2019; 90: 430-439

[102] Hale MF, Rahman I, Drew K et al. Magnetically steerable gastric capsule endoscopy is equivalent to flexible endoscopy in the detection of markers in an excised porcine stomach model: results of a randomized trial. Endoscopy 2015; 47: 650-653

[103] Zou WB, Hou XH, Xin L et al. Magnetic-controlled capsule endoscopy vs. gastroscopy for gastric diseases: a two-center self-controlled comparative trial. Endoscopy 2015; 47: 525-528

[104] Liao Z, Hou X, Lin-Hu EQ et al. Accuracy of magnetically controlled capsule endoscopy, compared with conventional gastroscopy, in detection of gastric diseases. Clin Gastroenterol Hepatol 2016; 14: 1266-1273.e1

[105] Stone J, Grover K, Bernstein CN. The use of capsule endoscopy for diagnosis of iron deficiency anemia: a retrospective analysis. J Clin Gastroenterol 2020; 54: 452-458

[106] Contaldo A, Losurdo G, Albano F et al. The spectrum of small intestinal lesions in patients with unexplained iron deficiency anemia detected by video capsule endoscopy. Medicina (Kaunas) 2019; 55: 59

[107] Garrido DuránC, Iyo MiyashiroE, Páez CumpaC et al. Rentabilidad de la cápsula endoscópica en mujeres premenopáusicas con anemia ferropénica [Diagnostic yield of video capsule endoscopy in premenopausal women with iron-deficiency anemia]. Gastroenterol Hepatol 2015; 38: 373-378

[108] Xavier S, Magalhães ], Rosa B et al. Impact of small bowel capsule endoscopy in iron deficiency anemia: influence of patient'sage on diagnostic yield. Arq Gastroenterol 2018; 55: 242-246

[109] Olano C, Pazos X, Avendaño K et al. Diagnostic yield and predictive factors of findings in small-bowel capsule endoscopy in the setting of iron-deficiency anemia. Endosc Int Open 2018; 6: E688-E693

[110] Yung DE, Rondonotti E, Giannakou A et al. Capsule endoscopy in young patients with iron deficiency anaemia and negative bidirectional gastrointestinal endoscopy. United European Gastroenterol J 2017; 5: 974-981

[111] Milano A, Balatsinou C, Filippone A et al. A prospective evaluation of iron deficiency anemia in the $\mathrm{Gl}$ endoscopy setting: role of standard endoscopy, videocapsule endoscopy, and CT-enteroclysis. Gastrointest Endosc 2011; 73: 1002-1008

[112] Limsrivilai J, Srisajjakul S, Pongprasobchai S et al. A prospective blinded comparison of video capsule endoscopy versus computed tomography enterography in potential small bowel bleeding: clinical utility of computed tomography enterography. J Clin Gastroenterol 2017; 51: 611-618 
[113] Kim SH, Keum B, Chun H] et al. Efficacy and implications of a 48-h cutoff for video capsule endoscopy application in overt obscure gastrointestinal bleeding. Endosc Int Open 2015; 3: E334-E338

[114] Gomes C, Pinho R, Rodrigues A et al. Impact of the timing of capsule endoscopy in overt obscure gastrointestinal bleeding on yield and rebleeding rate - is sooner than $14 \mathrm{~d}$ advisable? World J Gastrointest Endosc 2018; 10: 74-82

[115] lio S, Oka S, Tanaka S et al. Clinical utility of emergency capsule endoscopy for diagnosing the source and nature of ongoing overt obscure gastrointestinal bleeding. Gastroenterol Res Pract 2019; 2019: 5496242

[116] Segarajasingam DS, Hanley SC, Barkun AN et al. Randomized controlled trial comparing outcomes of video capsule endoscopy with push enteroscopy in obscure gastrointestinal bleeding. Can J Gastroenterol Hepatol 2015; 29: 85-90

[117] Law R, Varayil JE, WongKeeSong LM et al. Assessment of multimodality evaluations of obscure gastrointestinal bleeding. World J Gastroenterol 2017; 23: 614-621

[118] Tseng CM, Lin IC, Chang CY et al. Role of computed tomography angiography on the management of overt obscure gastrointestinal bleeding. PLoS One 2018; 13: e0193793

[119] Yung DE, Sykes C, Koulaouzidis A. The validity of suspected blood indicator software in capsule endoscopy: a systematic review and meta-analysis. Expert Rev Gastroenterol Hepatol 2017; 11: 43-51

[120] Arieira C, Monteiro S, Dias de Castro F et al. Capsule endoscopy: Is the software TOP 100 a reliable tool in suspected small bowel bleeding? Dig Liver Dis 2019; 51: 1661-1664

[121] Beg S, Wronska E, Araujo I et al. Use of rapid reading software to reduce capsule endoscopy reading times while maintaining accuracy. Gastrointest Endosc 2020; 91: 1322-1327

[122] Tsuboi A, Oka S, Aoyama K et al. Artificial intelligence using a convolutional neural network for automatic detection of small-bowel angioectasia in capsule endoscopy images. Dig Endosc 2020; 32: 382-390

[123] Leenhardt R, Vasseur P, Li C et al. A neural network algorithm for detection of $\mathrm{Gl}$ angiectasia during small-bowel capsule endoscopy. Gastrointest Endosc 2019; 89: 189-194

[124] Aoki T, Yamada A, Kato Y et al. Automatic detection of blood content in capsule endoscopy images based on a deep convolutional neural network. J Gastroenterol Hepatol 2020; 35: 1196-1200

[125] Ding Z, Shi H, Zhang $\mathrm{H}$ et al. Gastroenterologist-level identification of small-bowel diseases and normal variants by capsule endoscopy using a deep-learning model. Gastroenterology 2019; 157: 10441054.e5

[126] Fan S, Xu L, Fan Y et al. Computer-aided detection of small intestinal ulcer and erosion in wireless capsule endoscopy images. Phys Med Biol 2018; 63: 165001

[127] Alaskar H, Hussain A, Al-Aseem N et al. Application of convolutional neural networks for automated ulcer detection in wireless capsule endoscopy images. Sensors (Basel) 2019; 19: 1265

[128] Wang S, Xing Y, Zhang L et al. Deep convolutional neural network for ulcer recognition in wireless capsule endoscopy: experimental feasibility and optimization. Comput Math Methods Med 2019: doi:10.1155/2019/7546215

[129] Klang E, Barash Y, Margalit RY et al. Deep learning algorithms for automated detection of Crohn's disease ulcers by video capsule endoscopy. Gastrointest Endosc 2020; 91: 606-613.e2

[130] Zhou T, Han G, Li BN et al. Quantitative analysis of patients with celiac disease by video capsule endoscopy: A deep learning method. Comput Biol Med 2017; 85: 1-6

[131] Yuan Y, Meng MQ. Deep learning for polyp recognition in wireless capsule endoscopy images. Med Phys 2017; 44: 1379-1389
[132] Saito H, Aoki T, Aoyama K et al. Automatic detection and classification of protruding lesions in wireless capsule endoscopy images based on a deep convolutional neural network. Gastrointest Endosc 2020; 92: 144-151.e1

[133] Testoni PA, Mariani A, Aabakken L et al. Papillary cannulation and sphincterotomy techniques at ERCP: European Society of Gastrointestinal Endoscopy (ESGE) Clinical Guideline. Endoscopy 2016; 48: 657-683

[134] Skinner M, Popa D, Neumann H et al. ERCP with the overtube-assisted enteroscopy technique: a systematic review. Endoscopy 2014; 46: $560-572$

[135] Sahar N, La Selva D, Gluck M et al. The ASGE grading system for ERCP can predict success and complication rates in a tertiary referral hospital. Surg Endosc 2019; 33: 448-453

[136] Inamdar S, Slattery E, Sejpal DV et al. Systematic review and metaanalysis of single-balloon enteroscopy-assisted ERCP in patients with surgically altered $\mathrm{Gl}$ anatomy. Gastrointest Endosc 2015; 82: 9-19

[137] Nakai Y, Kogure H, Yamada A et al. Endoscopic management of bile duct stones in patients with surgically altered anatomy. Dig Endosc 2018; 30: (Suppl. 01): 67-74

[138] Park TY, Song T]. Recent advances in endoscopic retrograde cholangiopancreatography in Billroth II gastrectomy patients: A systematic review. World J Gastroenterol 2019; 25: 3091-3107

[139] Tang Z, Yang Y, Yang Z et al. Early precut sphincterotomy does not increase the risk of adverse events for patients with difficult biliary access: A systematic review of randomized clinical trials with metaanalysis and trial sequential analysis. Medicine (Baltimore) 2018; 97: e12213

[140] Chen J, Wan JH, Wu DY et al. Assessing quality of precut sphincterotomy in patients with difficult biliary access: an updated meta-analysis of randomized controlled trials. J Clin Gastroenterol 2018; 52: $573-578$

[141] Sundaralingam P, Masson P, Bourke MJ. Early precut sphincterotomy does not increase risk during endoscopic retrograde cholangiopancreatography in patients with difficult biliary access: a meta-analysis of randomized controlled trials. Clin Gastroenterol Hepatol 2015; 13: 1722-1729.e2

[142] Choudhary A, Winn J, Siddique $S$ et al. Effect of precut sphincterotomy on post-endoscopic retrograde cholangiopancreatography pancreatitis: a systematic review and meta-analysis. World J Gastroenterol 2014; 20: 4093-4101

[143] Dumonceau JM, Andriulli A, Elmunzer B] et al. Prophylaxis of postERCP pancreatitis: European Society of Gastrointestinal Endoscopy (ESGE) Guideline - updated June 2014. Endoscopy 2014; 46: 799815

[144] Wan J, Ouyang Y, Yu C et al. Comparison of EUS with MRCP in idiopathic acute pancreatitis: a systematic review and meta-analysis. Gastrointest Endosc 2018; 87: 1180-1188.e9

[145] Zerboni G, Signoretti M, Crippa S et al. Capurso G. Systematic review and meta-analysis: Prevalence of incidentally detected pancreatic cystic lesions in asymptomatic individuals. Pancreatology 2019; 19 : 2-9

[146] Vanella G, Arcidiacono PG, Capurso G. Chronic asymptomatic pancreatic hyperenzymemia (CAPH): Meta-analysis of pancreatic findings at second-level imaging. Pancreatology 2019; 19: 237-244

[147] Ashkar M, Gardner TB. Role of endoscopic ultrasound in pancreatic diseases: a systematic review. Minerva Gastroenterol Dietol 2014; 60: $227-245$

[148] Shen Z, Munker S, Zhou B et al. The accuracies of diagnosing pancreas divisum by magnetic resonance cholangiopancreatography and endoscopic ultrasound: a systematic review and meta-analysis. Sci Rep 2016; 6: 35389 
[149] Kalva NR, Vanar V, Forcione D et al. Efficacy and safety of lumen apposing self-expandable metal stents for EUS guided cholecystostomy: a meta-analysis and systematic review. Can J Gastroenterol Hepatol 2018; 2018: 7070961

[150] Luk SW, Irani S, Krishnamoorthi R et al. Endoscopic ultrasoundguided gallbladder drainage versus percutaneous cholecystostomy for high risk surgical patients with acute cholecystitis: a systematic review and meta-analysis. Endoscopy 2019; 51: 722-732

[151] Fusaroli P, Napoleon B, Gincul R et al. The clinical impact of ultrasound contrast agents in EUS: a systematic review according to the levels of evidence. Gastrointest Endosc 2016; 84: 587-596.e10

[152] Zhang B, Zhu F, Li P et al. Endoscopic ultrasound elastography in the diagnosis of pancreatic masses: A meta-analysis. Pancreatology 2018; 18: 833-840

[153] Tse F, Yuan Y, Moayyedi P et al. Double-guidewire technique in difficult biliary cannulation for the prevention of post-ERCP pancreatitis: a systematic review and meta-analysis. Endoscopy 2017; 49: 15-26

[154] Tian G, Bao H, Li J et al. Systematic review and meta-analysis of diagnostic accuracy of endoscopic ultrasound (EUS)-guided fineneedle aspiration (FNA) using 22-gauge and 25-gauge needles for pancreatic masses. Med Sci Monit 2018; 24: 8333-8341

[155] Li DF, Yang MF, Chang X et al. Endocut versus conventional blended electrosurgical current for endoscopic biliary sphincterotomy: a meta-analysis of complications. Dig Dis Sci 2019; 64: 2088-2094

[156] Coutinho LMA, Bernardo WM, Rocha RS et al. Early endoscopic retrograde cholangiopancreatography versus conservative treatment in patients with acute biliary pancreatitis: systematic review and meta-analysis of randomized controlled trials. Pancreas 2018; 47: 444-453

[157] Jin Z, Wei Y, Tang X et al. Single-operator peroral cholangioscope in treating difficult biliary stones: A systematic review and meta-analysis. Dig Endosc 2019; 31: 256-269

[158] Crockett S, Falck-Ytter Y, Wani S et al. Acute pancreatitis guideline. Gastroenterology 2018; 154: 1102

[159] Jayaraj M, Mohan BP, Dhindsa BS et al. Periampullary diverticula and ERCP outcomes: a systematic review and meta-analysis. Dig Dis Sci 2019; 64: 1364-1376

[160] ASGE Standards of Practice Committee, Buxbaum JL, Abbas Fehmi SM et al. ASGE guideline on the role of endoscopy in the evaluation and management of choledocholithiasis. Gastrointest Endosc 2019; 89: 1075-1105.e15

[161] Vege SS, Ziring B, Jain R et al. American Gastroenterological Association Institute Guideline on the diagnosis and management of asymptomatic neoplastic pancreatic cysts. Gastroenterology 2015; 148: 819-822

[162] Tanaka M, Fernández-Del Castillo C, Kamisawa T et al. Revisions of international consensus Fukuoka guidelines for the management of IPMN of the pancreas. Pancreatology 2017; 17: 738-753

[163] European Study Group on Cystic Tumours of the Pancreas. European evidence-based guidelines on pancreatic cystic neoplasms. Gut 2018; 67: 789-804

[164] Marchegiani G, Andrianello S, Borin A et al. Systematic review, metaanalysis, and a high-volume center experience supporting the new role of mural nodules proposed by the updated 2017 international guidelines on IPMN of the pancreas. Surgery 2018; 163: 1272-1279

[165] van Huijgevoort NCM, Del Chiaro M, Wolfgang CL et al. Diagnosis and management of pancreatic cystic neoplasms: current evidence and guidelines. Nat Rev Gastroenterol Hepatol 2019; 16: 676-689

[166] Dumonceau JM, Deprez PH, Jenssen C et al. Indications, results, and clinical impact of endoscopic ultrasound (EUS)-guided sampling in gastroenterology: European Society of Gastrointestinal Endoscopy (ESGE) Clinical Guideline - Updated January 2017. Endoscopy 2017; 49: 695-714
[167] Carrara S, Di Leo M, Grizzi F et al. EUS elastography (strain ratio) and fractal-based quantitative analysis for the diagnosis of solid pancreatic lesions. Gastrointest Endosc 2018; 87: 1464-1473

[168] Ignee A, Jenssen C, Arcidiacono PG et al. Endoscopic ultrasound elastography of small solid pancreatic lesions: a multicenter study. Endoscopy 2018; 50: 1071-1079

[169] Dietrich CF, Sahai AV, D'Onofrio M et al. Differential diagnosis of small solid pancreatic lesions. Gastrointest Endosc 2016; 84: $933-$ 940

[170] Costache MI, Cazacu IM, Dietrich CF et al. Clinical impact of strain histogram EUS elastography and contrast-enhanced EUS for the differential diagnosis of focal pancreatic masses: A prospective multicentric study. Endosc Ultrasound 2020; 9: 116-121

[171] Le Berre C, Sandborn WJ, Aridhi S et al. Application of artificial intelligence to gastroenterology and hepatology. Gastroenterology 2020; 158: 76-94.e2

[172] Schlottmann F, Luckett DJ, Fine J et al. Laparoscopic Heller myotomy versus peroral endoscopic myotomy (POEM) for achalasia: a systematic review and meta-analysis. Ann Surg 2018; 267: 451-460

[173] Werner YB, Hakanson B, Martinek J et al. Endoscopic or surgical myotomy in patients with idiopathic achalasia. NEJM 2019; 381: 2219-2229

[174] Jacques J, Pagnon L, Hure F et al. Peroral endoscopic pyloromyotomy is efficacious and safe for refractory gastroparesis: prospective trial with assessment of pyloric function. Endoscopy 2019; 51: 40-49

[175] Bernardot L, Roman S, Barret M et al. Efficacy of per-oral endoscopic myotomy for the treatment of non-achalasia esophageal motor disorders. Surg Endosc 2020; 34: 5508-5515

[176] Hernández Mondragón OV, Solórzano Pineda MO, Blancas Valencia JM. Zenker's diverticulum: Submucosal tunneling endoscopic septum division (Z-POEM). Dig Endosc 2018; 30: 124

[177] Shoji Y, Takeuchi H, Goto O et al. Optimal minimally invasive surgical procedure for gastric submucosal tumors. Gastric Cancer 2018; 21: 508-515

[178] Goto O, Takeuchi H, Sasaki M et al. Laparoscopy-assisted endoscopic full-thickness resection of gastric subepithelial tumors using a nonexposure technique. Endoscopy 2016; 48: 1010-1015

[179] Hedjoudje A, Abu Dayyeh BK, Cheskin LJ et al. Efficacy and safety of endoscopic sleeve gastroplasty: a systematic review and meta-analysis. Clin Gastroenterol Hepatol 2020; 18: 1043-1053.e4

[180] Fiorillo C, Quero G, Vix M et al. 6-month gastrointestinal quality of life $(\mathrm{QoL})$ results after endoscopic sleeve gastroplasty and laparoscopic sleeve gastrectomy: a propensity score analysis. Obes Surg 2020; 30: 1944-1951

[181] Fayad L, Adam A, Schweitzer M et al. Endoscopic sleeve gastroplasty versus laparoscopic sleeve gastrectomy: a case-matched study. Gastrointest Endosc 2019; 89: 782-788

[182] Lorenzo D, Guilbaud T, Gonzalez JM et al. Endoscopic treatment of fistulas after sleeve gastrectomy: a comparison of internal drainage versus closure. Gastrointest Endosc 2018; 87: 429-437

[183] Bège T, Emungania O, Vitton V et al. An endoscopic strategy for management of anastomotic complications from bariatric surgery: a prospective study. Gastrointest Endosc 2011; 73: 238-244

[184] Bouchard S, Eisendrath P, Toussaint E et al. Trans-fistulary endoscopic drainage for post-bariatric abdominal collections communicating with the upper gastrointestinal tract. Endoscopy 2016; 48: 809-816

[185] van Baar ACG, Holleman F, Crenier L et al. Endoscopic duodenal mucosal resurfacing for the treatment of type 2 diabetes mellitus: one year results from the first international, open-label, prospective, multicentre study. Gut 2020; 69: 295-303 
[186] Gupta S, Miskovic D, Bhandari P et al. A novel method for determining the difficulty of colonoscopic polypectomy. Frontline Gastroenterol 2013; 4: 244-248

[187] Sansone S, Ragunath K, Bianco MA et al. Clinical utility of the SMSA grading tool for the management of colonic neoplastic lesions. Dig Liver Dis 2017; 49: 518-522

[188] Barosa R, Mohammed N, Rembacken B. Risk stratification of colorectal polyps for predicting residual or recurring adenoma using the Size/Morphology/Site/Access score. United European Gastroenterol J 2018; 6: 630-638

[189] Sidhu M, Tate DJ, Desomer L et al. The size, morphology, site, and access score predicts critical outcomes of endoscopic mucosal resection in the colon. Endoscopy 2018; 50: 684-692

[190] Currie AC, Merriman H, Nadia Shah Gilani S et al. Validation of the size morphology site access score in endoscopic mucosal resection of large polyps in a district general hospital. Ann R Coll Surg Engl 2019; 101: 558-562

[191] Tate DJ, Desomer L, Klein A et al. Adenoma recurrence after piecemeal colonic EMR is predictable: the Sydney EMR recurrence tool. Gastrointest Endosc 2017; 85: 647-656.e6

[192] Silva JC, Pinho R, Fernades C et al. Prediction of adenoma recurrence after piecemeal endoscopic mucosal resection: interobserver agreement and utilization of the Sydney EMR recurrence tool. Scand J Gastroenterol 2020; 55: 492-496
[193] Albéniz E, Fraile M, Ibáñez B et al. A scoring system to determine risk of delayed bleeding after endoscopic mucosal resection of large colorectal lesions. Clin Gastroenterol Hepatol 2016; 14: 1140-1147

[194] Bahin FF, Rasouli KN, Byth K et al. Prediction of clinically significant bleeding following wide-field endoscopic resection of large sessile and laterally spreading colorectal lesions: a clinical risk score. Am J Gastroenterol 2016; 111: 1115-1122

[195] Albéniz E, Gimeno-García AZ, Fraile M et al. Clinical validation of risk scoring systems to predict risk of delayed bleeding after EMR of large colorectal lesions. Gastrointest Endosc 2020; 91: 868-878.e3

[196] Burgess NG, Bassan MS, McLeod D et al. Deep mural injury and perforation after colonic endoscopic mucosal resection: a new classification and analysis of risk factors. Gut 2017; 66: 1779-1789

[197] Hong SN, Byeon JS, Lee BI et al. Prediction model and risk score for perforation in patients undergoing colorectal endoscopic submucosal dissection. Gastrointest Endosc 2016; 84: 98-108

[198] Seo M, Song EM, Cho JW et al. A risk-scoring model for the prediction of delayed bleeding after colorectal endoscopic submucosal dissection. Gastrointest Endosc 2019; 89: 990-998.e2

[199] Matsumoto S, Uehara T, Mashima H. Construction of a preoperative scoring system to predict the difficulty level of colorectal endoscopic submucosal dissection. PLoS One 2019; 14: e0219096 